\title{
Direct Causticizing for Black Liquor Gasification in a Circulating Fluidized Bed
}

\author{
Final Project Report \\ DE-FG36-06GO16042
}

Project Period: September 30, 2006 - August 31, 2009

Scott Sinquefield, 404-894-5700, scott.sinquefield@ipst.gatech.edu

Xiaoyan Zeng

Alan W. Ball

Institute of Paper Science and Technology at GA Tech

500 Tenth St. NW

Atlanta, GA 30332-0620 
DOCUMENT AVAILABILITY:

Reports are available free via the U.S. Department of Energy (DOE) Information Bridge:

Web Site http://www.osti.gov/bridge

Reports are available to DOE employees, DOE contractors, Energy Technology Data Exchange (ETDE) representatives, and Informational Nuclear Information System (INIS) representatives from the following source:

Office of Scientific and Technical Information

P.O. Box 62

Oak Ridge, TN 37831

Tel: (865) 576-8401

Fax: (865) 576-5728

E-mail: reports@osti.gov

Web Site: http://www.osti.gov/contact.html

Acknowledgment: This report is based upon work supported by the U. S. Department of Energy under Award \# DE-FG36-06GO16042, which cost-sharing funds coming for Weyerhaeuser Co., Georgia Pacific Corp., and the State of Georgia.

Disclaimer: Any findings, opinions, and conclusions or recommendations expressed in this report are those of the author(s) and do not necessarily reflect the views of the Department of Energy.

Proprietary Data Notice: If there is any patentable material or protected data in the report, the recipient, consistent with the data protection provisions of the award, must mark the appropriate block in Section K of the DOE F 241.3, clearly specify it here, and identify them on appropriate pages of the report. Other than patentable material or protected data, reports must not contain any proprietary data (limited rights data), classified information, information subject to export control classification, or other information not subject to release. Protected data is specific technical data, first produced in the performance of the award, which is protected from public release for a period of time by the terms of the award agreement. Reports delivered without such notice may be deemed to have been furnished with unlimited rights, and the Government assumes no liability for the disclosure, reproduction or use of such reports. 


\section{Table of Contents}

Executive Summary $\quad 5$

Introduction $\quad 6$

Background

$\begin{array}{ll}\text { Experimental } & 13\end{array}$

Results

$\begin{array}{lc}\text { Experimental results } & 14\end{array}$

$\begin{array}{ll}\text { Material and Energy Balance } & 17\end{array}$

$\begin{array}{ll}\text { Economics } & 21\end{array}$

Conclusions- proposed process is viable $\quad 22$

Recommendations- build pilot $\quad 22$

$\begin{array}{ll}\text { References } & 23\end{array}$

Appendix A. Experimental Details $\quad 25$

Appendix B. Experimental Data $\quad 30$

Appendix C. Process Simulation Details $\quad 35$

Appendix D. Economic Assessment 38

\section{Lists of Figures, Tables and Appendices}

Figure 1. Black liquor gasification process with titanate direct causticization $\quad 8$

Figure 2. Experimental results of gasifying black liquor with titanate... 9

Figure 3. FactSage equilibrium prediction of $\mathrm{CO}_{2}$ concentrations... 10

Figure 4. Experimental results of gasifying black liquor with titanate... 11

Figure 5. Hydroxide recovered from char formed by BLG with titanate 15

Figure 6. Proposed process for pressurized BLG with titanate direct causticizing. 18

Table 1. High Yield Pulping Processes 6

Table 2. Black liquor elemental composition used in this work 13

Table 3. Results of titration of char produced from BLG of Ti-doped black liquor 14

Table 4. Leaching of twice-used titanate 16

Table 5. Key flow rates for Figure 6 19

Table 6. Gas composition leaving gasifier (stream 6) in Figure $6 \quad 20$

Table 7. Key process data from Figure $6 \quad 20$

Table 8. NPV and IRR as a Function of Fuel Cost 21

Figure A1. IPST's Pressurized Entrained Flow Reactor 25

Figure A2. Another view of the PEFR. 26

Figure A3. Diagram of the PEFR showing pressure vessel 27

Figure A4. The leaching apparatus $\quad 29$

Table B1. Experimental data 31

Table B2. Leaching data 33

Table C1. Model black liquor composition and properties 35

Table D1. Reference Mill Basis Data 38

Table D2. HTBLG Chemical Recovery Data 39 
Table D3. Titanate ChemCad Balance Basis and Assumptions 40

Table D4. Capital Estimates Assumptions 41

Table D5. Summary of Total Installed Cost of [9] 42

Table D6. Summary of Total Installed Cost of Proposed Process 43

Table D7. Chemicals, Fuel Oil, and Electricity Costs (2009) 43

Table D8. Annual Chemicals, Fuel Oil, and Electricity Usages [9] 44

Table D9. Annualized O\&M Costs 44

Table D10. Economic Assumptions $\quad 45$

Table D11. Annual Costs for the Proposed Process 46

Table D12. NPV and IRR as a Function of Fuel Cost 45 


\section{Executive Summary}

Gasification of black liquor (BLG) has distinct advantages over direct combustion in Tomlinson recovery boilers. In this project we seek to resolve causticizing issues in order to make pressurized BLG even more efficient and cost-effective. One advantage of BLG is that the inherent partial separation of sulfur and sodium during gasification lends itself to the use of proven high yield variants to conventional kraft pulping which require just such a separation. Processes such as polysulfide, split sulfidity, ASAQ, and MSSAQ can increase pulp yield from $1 \%$ to $10 \%$ over conventional kraft but require varying degrees of sulfur/sodium separation, which requires additional [and costly] processing in a conventional Tomlinson recovery process. However during gasification, the sulfur is partitioned between the gas and smelt phases, while the sodium all leaves in the smelt; thus creating the opportunity to produce sulfur-rich and sulfur-lean white liquors for specialty pulping processes.

A second major incentive of BLG is the production of a combustible product gas, rich in $\mathrm{H}_{2}$ and CO. This product gas (a.k.a. "syngas") can be used in gas turbines for combined cycle power generation (which is twice as efficient as the steam cycle alone), or it can be used as a precursor to form liquid fuels, such as dimethyl ether or Fischer Tropsh diesel.

There is drawback to BLG, which has the potential to become a third major incentive if this work is successful. The causticizing load is greater for gasification of black liquor than for combustion in a Tomlinson boiler. So implementing BLG in an existing mill would require costly increases to the causticizing capacity. In situ causticizing [within the gasifier] would handle the entire causticizing load and therefore eliminate the lime cycle entirely. Previous work by the author and others has shown that titanate direct causticizing (i.e. in situ) works quite well for high-temperature BLG $\left(950^{\circ} \mathrm{C}\right)$, but was limited to pressures below about 5 bar. It is desirable however to operate BLG at 20-30 bar for efficiency reasons related to either firing the syngas in a turbine, or catalytically forming liquid fuels. This work focused on achieving high direct causticizing yields at 20 bars pressure.

The titanate direct causticizing reactions are inhibited by $\mathrm{CO}_{2}$. Previous work has shown that the partial pressure of $\mathrm{CO}_{2}$ should be kept below about 0.5 bar in order for the process to work. This translates to a total reactor pressure limit of about 5 bar for airblown BLG, and only 2 bar for $\mathrm{O}_{2}$-blown BLG. In this work a process was developed in which the $\mathrm{CO}_{2}$ partial pressure could be manipulated to a level under 0.5 bar with the total system pressure at 10 bar during $\mathrm{O}_{2}$-blown BLG. This fell short of our 20 bar goal but still represents a substantial increase in the pressure limit. A material and energy balance was performed, as well as first-pass economics based on capital and utilities costs. Compared to a reference case of using BLG with a conventional lime cycle [Larson, 2003], the IRR and NVP were estimated for further replacing the lime kiln with direct causticizing. The economics are strongly dependent on the price of lime kiln fuel. At $\$ 6 / \mathrm{mmBTU}$ the lime cycle is the clear choice. At $\$ 8 / \mathrm{mmBTU}$ the NPV is $\$ 10 \mathrm{M}$ with IRR of $17 \%$. At $\$ 12 / \mathrm{mmBTU}$ the NPV is $\$ 45 \mathrm{M}$ with IRR of $36 \%$.

To further increase the total allowable pressure, the $\mathrm{CO}_{2}$ could be further decreased by further decreasing the temperature. Testing should be done at $750 \mathrm{C}$. Also a small pilot should be built. 


\section{Introduction}

Gasification of black liquor (BLG) has distinct advantages over direct combustion in Tomlinson recovery boilers $[1,8,21]$. In this project we address causticizing issues which, if resolved, will make BLG even more efficient and cost-effective. First we will discuss the major incentives of BLG over Tomlinson combustion. The inherent [partial] separation of sulfur and sodium during gasification lends itself to the use of proven high yield variants to conventional kraft pulping which require just such a separation. Processes such as polysulfide, split sulfidity, ASAQ, and MSSAQ can increase pulp yield from $1 \%$ to $10 \%$ over conventional kraft but require varying degrees of sulfur/sodium separation, which requires additional [and costly] processing in a conventional Tomlinson recovery process. However during gasification, the sulfur is partitioned between the gas and smelt phases, while the sodium all leaves in the smelt; thus creating the opportunity to produce sulfur-rich and sulfur-lean white liquors for specialty pulping processes. Some promising possibilities are shown in Table 1.

\begin{tabular}{|l|c|c|}
\hline \multicolumn{2}{|c|}{ Table 1. Some High Yield Pulping processes } \\
\hline Process & Yield increase & $\begin{array}{c}\% \text { of sulfur needed in gas phase } \\
\text { (i.e. degree of sulfur/sodium separation) }\end{array}$ \\
\hline Straight Kraft & - & $0 \%$ \\
\hline Kraft w/Split Sulfidity & $0.5-1 \%$ & $10 \%$ \\
\hline $\begin{array}{l}\text { Kraft w/Polysulfide \& } \\
\text { Anthroquinone }\end{array}$ & $2-3 \%$ & $40 \%$ \\
\hline MSSAQ & $2-6 \%$ & $90 \%$ \\
\hline ASAQ & $1-10 \%$ & $100 \%$ \\
\hline
\end{tabular}

The potential yield increase varies with the type of product (i.e. linerboard, tissue, etc.) so approximate ranges are given. High degrees of separation, such as $90-100 \%$ are limited to low temperature $(600 \mathrm{C})$ steam reforming of black liquor and are not likely to be achieved in this case. However, levels of sulfur separation to about $50 \%$ as a function of temperature to $1100 \mathrm{C}$ have been well documented.

A second major incentive of BLG is the production of a combustible product gas, rich in $\mathrm{H}_{2}$ and CO. This product gas (a.k.a. "syngas") can be used in gas turbines for combined cycle power generation (which is twice as efficient as the steam cycle alone), or it can be used as a precursor to form motor fuels, such as dimethyl ether or Fischer Tropsh diesel. However, there is a major drawback to BLG, which has the potential to become a third major incentive. That is that the causticizing load is greater for gasification of black liquor than for combustion in a Tomlinson boiler. This increase must at least be mitigated if black liquor gasifiers are to become a viable alternative to Tomlinson boilers in that the candidate mill's existing lime cycle could be utilized as-is without costly capacity increase. Further, if complete causticization can be accomplished directly during gasification, then the costly lime cycle could be eliminated along with the recovery boiler. 
In the Tomlinson boiler the sulfur and sodium (and potassium) combine to form $\mathrm{Na}_{2} \mathrm{~S}$ (and $\mathrm{K}_{2} \mathrm{~S}$ ), which leaves the boiler as molten smelt. The remaining sodium forms sodium carbonate $\left(\mathrm{Na}_{2} \mathrm{CO}_{3}\right)$, which comprises the remainder of the smelt. After exiting the boiler the smelt enters the recausticizing plant, which converts most of the $\mathrm{Na}_{2} \mathrm{CO}_{3}$ to $\mathrm{NaOH}$; the carbonate is converted to $\mathrm{CO}_{2}$. The $\mathrm{Na}_{2} \mathrm{~S}$ remains unchanged in this step. The $\mathrm{NaOH}$ and $\mathrm{Na}_{2} \mathrm{~S}$ (along with some unconverted $\mathrm{Na}_{2} \mathrm{CO}_{3}$ ) leave the lime cycle as fresh white liquor for the pulping operation. However if black liquor is instead gasified, a portion of the sulfur leaves with the gas stream as $\mathrm{H}_{2} \mathrm{~S}$ and $\operatorname{COS}[9,19]$. While this is good for making specialty pulping liquors, it does leave excess sodium which leads to additional $\mathrm{Na}_{2} \mathrm{CO}_{3}$, which adds to the recausticizing load. So if an aging Tomlinson boiler were replaced with a gasifier of equal black liquor firing capacity, the recausticizing plant would have to process more $\mathrm{Na}_{2} \mathrm{CO}_{3}$, which would require costly upgrades, and thus reduce the overall incentive for firms to adopt BLG.

For an estimate for lime kiln fuel cost savings (assuming complete in situ causticization is possible thus eliminating the lime cycle), a single mill uses $400-600 \mathrm{lbs} \mathrm{CaO}$ per ton of pulp is required for causticization depending the grade of pulp produced [17]. Using 500 $\mathrm{lb} /$ ton as an average, a 1000 tpd pulp mill would require 90,000 bbls of \#6 fuel oil per year to operate the lime kiln. At $\$ 60 / \mathrm{bbl}$, the savings is $\$ 5.4 \mathrm{M} / \mathrm{yr}$. There is also the cost associated with operating the lime cycle (slakers, pumps, clarifier, lime mud handling equipment, etc.) but that is partially offset by operation of the leaching equipment required for caustic recovery (leaching tanks, pumps, etc).

Previous work has shown that [in situ] titanate direct causticizing integrates well with BLG, but only at pressures below 5 bar. Since BLG is best performed at 15-30 bar, there is a clear incentive to overcome the pressure limitation of melding BLG with direct causticizing. This project specifically addresses that pressure limitation.

\section{Background}

Titanate direct causticizing within the gasifier has the potential to perform the causticizing step in situ during BLG and thus eliminate the need for the lime cycle entirely. In this system, sodium trititanate and sodium hexatitanate are added to the liquor to bind up the sodium as pentatitanate during gasification and allow the carbon to be released as $\mathrm{CO}$ or $\mathrm{CO}_{2}$. The main reactions involved are:

$$
\begin{gathered}
\mathrm{Na}_{2} \mathrm{CO}_{3}+3 \mathrm{TiO}_{2}(\mathrm{~s}) \leftrightarrow \mathrm{Na}_{2} \mathrm{O} \cdot 3 \mathrm{TiO}_{2}(\mathrm{~s})+\mathrm{CO}_{2}(\mathrm{~g}) \\
7 \mathrm{Na}_{2} \mathrm{CO}_{3}+5\left(\mathrm{Na}_{2} \mathrm{O} \cdot 3 \mathrm{TiO}_{2}\right)(\mathrm{s}) \leftrightarrow 3\left(4 \mathrm{Na}_{2} \mathrm{O} \cdot 5 \mathrm{TiO}_{2}\right)(\mathrm{s})+7 \mathrm{CO}_{2}(\mathrm{~g}) \\
\mathrm{Na}_{2} \mathrm{O} \cdot 6 \mathrm{TiO}_{2}(\mathrm{~s})+\mathrm{Na}_{2} \mathrm{CO}_{3}(\mathrm{~s}) \leftrightarrow 2\left(\mathrm{Na}_{2} \mathrm{O} \cdot 3 \mathrm{TiO}_{2}\right)(\mathrm{s})+\mathrm{CO}_{2}(\mathrm{~g})
\end{gathered}
$$

(Note that the Na-Ti compounds are typically abbreviated as NT3 for $\mathrm{Na}_{2} \mathrm{O} \cdot 3 \mathrm{TiO}_{2}, \mathrm{~N} 4 \mathrm{~T} 5$ for $4 \mathrm{Na}_{2} \mathrm{O} \cdot 5 \mathrm{TiO}_{2}$, and $\mathrm{NT} 6$ for $\mathrm{Na}_{2} \mathrm{O} \cdot 6 \mathrm{TiO}_{2}$ )

Reaction (5) is how make-up titanate is introduced to the system, and is not part of the cyclical chemistry. Reactions (1) and (2) are repeated cyclically however. In reaction (1) sodium is bound up with Ti to form the N4T5 (aka sodium pentatitanate). The solid phase (smelt) exiting the gasifier is sent to a leaching operation where the N4T5 is 
leached back to NT3 via reaction (3), while forming a sodium hydroxide solution which can be used for pulping:

$$
\begin{gathered}
3\left(4 \mathrm{Na}_{2} \mathrm{O} \cdot 5 \mathrm{TiO}_{2}\right)(\mathrm{s})+7 \mathrm{H}_{2} \mathrm{O} \leftrightarrow 14 \mathrm{NaOH}(\mathrm{aq})+5\left(\mathrm{Na}_{2} \mathrm{O} 3 \mathrm{TiO}_{2}\right)(\mathrm{s}) \\
2\left(\mathrm{Na}_{2} \mathrm{O} \cdot 3 \mathrm{TiO}_{2}\right)(\mathrm{s})+\mathrm{H}_{2} \mathrm{O} \leftrightarrow 2 \mathrm{NaOH}(\mathrm{aq})+\mathrm{Na}_{2} \mathrm{O} \cdot 6 \mathrm{TiO}_{2}(\mathrm{~s})
\end{gathered}
$$

Recent research has shown that some of the NT3 can be leached even further, via reaction (4), to produce NT6, which is even more desirable for the cyclic stoichiometry in that more sodium is bound up titanium during gasification and is then released during leaching. Magnussen [4] found that reaction (4) occurs to about $65 \%$ conversion at a leaching temperature of $80 \mathrm{C}$. The NT6 and NT3 solids are separated from the leachate and mixed with black liquor prior to entering the gasifier, where they react again according to reactions (1) and (2). The titanate compounds have very high melting points and are virtually insoluble; therefore the loss of titanate in this cyclic process is expected to be very small. Also, unlike the high quality $\mathrm{TiO}_{2}$ commonly used in paint, there is a cost effective rutile form of $\mathrm{TiO} 2$ that is acceptable for this application.

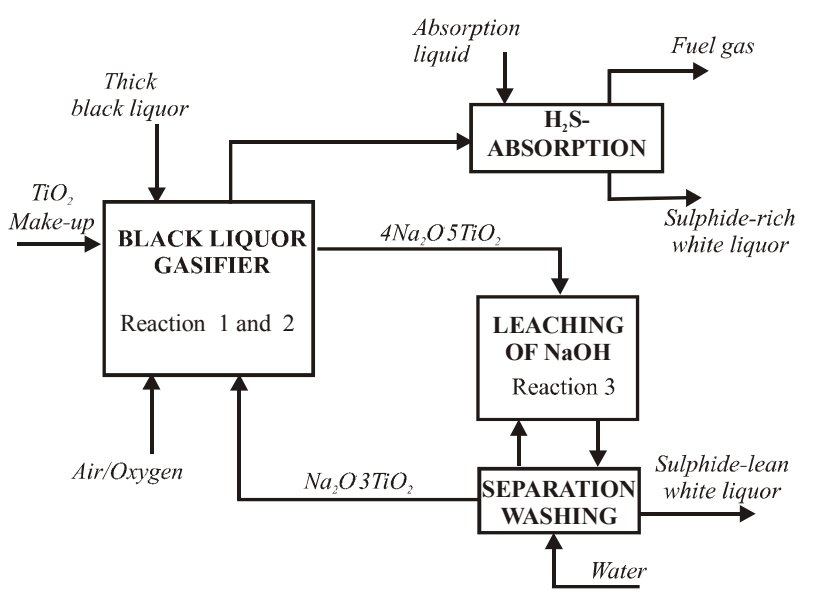

Figure 1. Black liquor gasification process with titanate direct causticization

The smelt would also contain a portion of the sulfur $\left(\mathrm{as}_{\mathrm{Na}} \mathrm{S}\right)$, which would dissolve in water and remain in the leachate with the $\mathrm{NaOH}$, effectively producing a white liquor that is hydroxide rich and sulfur lean. The remainder of the sulfur would leave the gasifier in the gas phase (mostly as $\mathrm{H}_{2} \mathrm{~S}$ and COS) and be recovered [most likely] in an absorption step. When recombined with a caustic scrubbing solution, the result would be a sulfurrich white liquor. The overall process is shown in Figure 1 above. Furthermore, the gasification conditions (temperature, air ratio, etc.) can be manipulated to vary the sulfur split to some degree. Consequently, white liquors of varying sulfidity can be obtained for the high yield pulping process variants.

The stoichiometry is promising. But are these reactions thermodynamically favourable, and do they occur with the time frame of gasification of the organic carbon in the black liquor? Several studies have shown they are and do [2,3,6,7,11-15]. Previous work by 
the authors [9] has evaluated the chemistry at high temperature entrained flow conditions (i.e. 5 seconds at 950C), and at low temperature steam reforming conditions (i.e. 50 hours at $600 \mathrm{C}$ in steam). Only the high temperature case is relevant here. Experimental results for the high temperature case are shown in Figure 2.

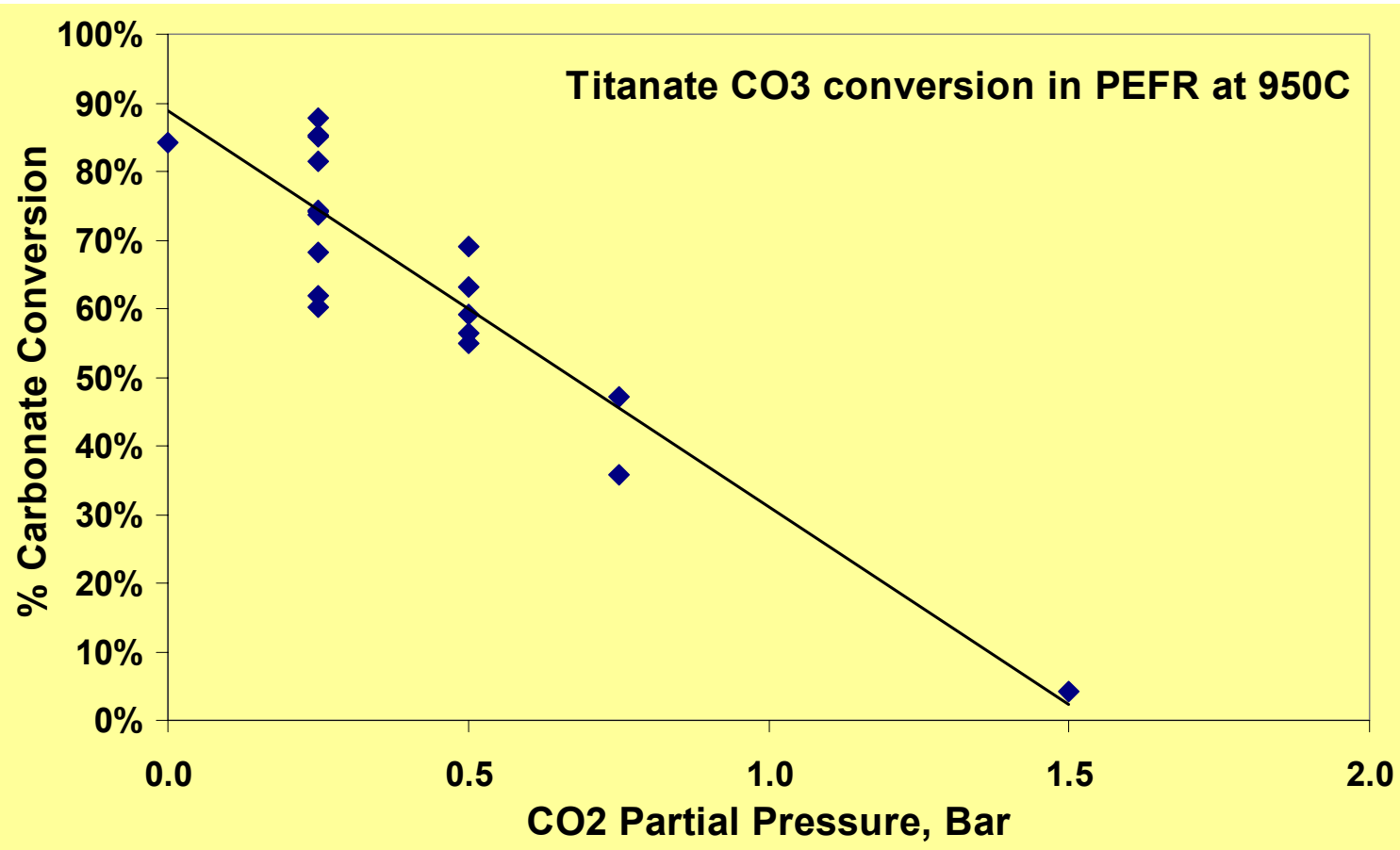

Figure 2. Experimental results of gasifying black liquor with titanate at 5 and 15 bars total pressure. The conversion of carbonate (i.e. formation of N4T5) decreases with increasing $\mathrm{CO}_{2}$ partial pressure as expected from Reaction (1).

To evaluate the viability of using titanates for direct causticizing during BLG at conditions found in a high temperature gasifier, NT3 was mixed with black liquor at a ratio sufficient to causticize all of the carbonate remaining in the gasified char. The mixture was dried and pulverized, and screened-sieved to 63-90 microns. The BL/NT3 powder was then gasified in IPST's pressurized entrained flow reactor (PEFR) at 950C for approximately 5 seconds. $\mathrm{CO}_{2}$ at varying concentration was used as the oxidizing gas: $5 \%$ and $10 \% \mathrm{CO}_{2}$ in $\mathrm{N} 2$ at 5 and 15 bars total pressure. The conversion of the causticizing reaction (1) is shown in Figure 2 as a function of $\mathrm{CO}_{2}$ partial pressure. $60 \%$ conversion is about the lowest acceptable level, which corresponds to 0.5 bar $\mathrm{CO}_{2}$ in the syngas. 


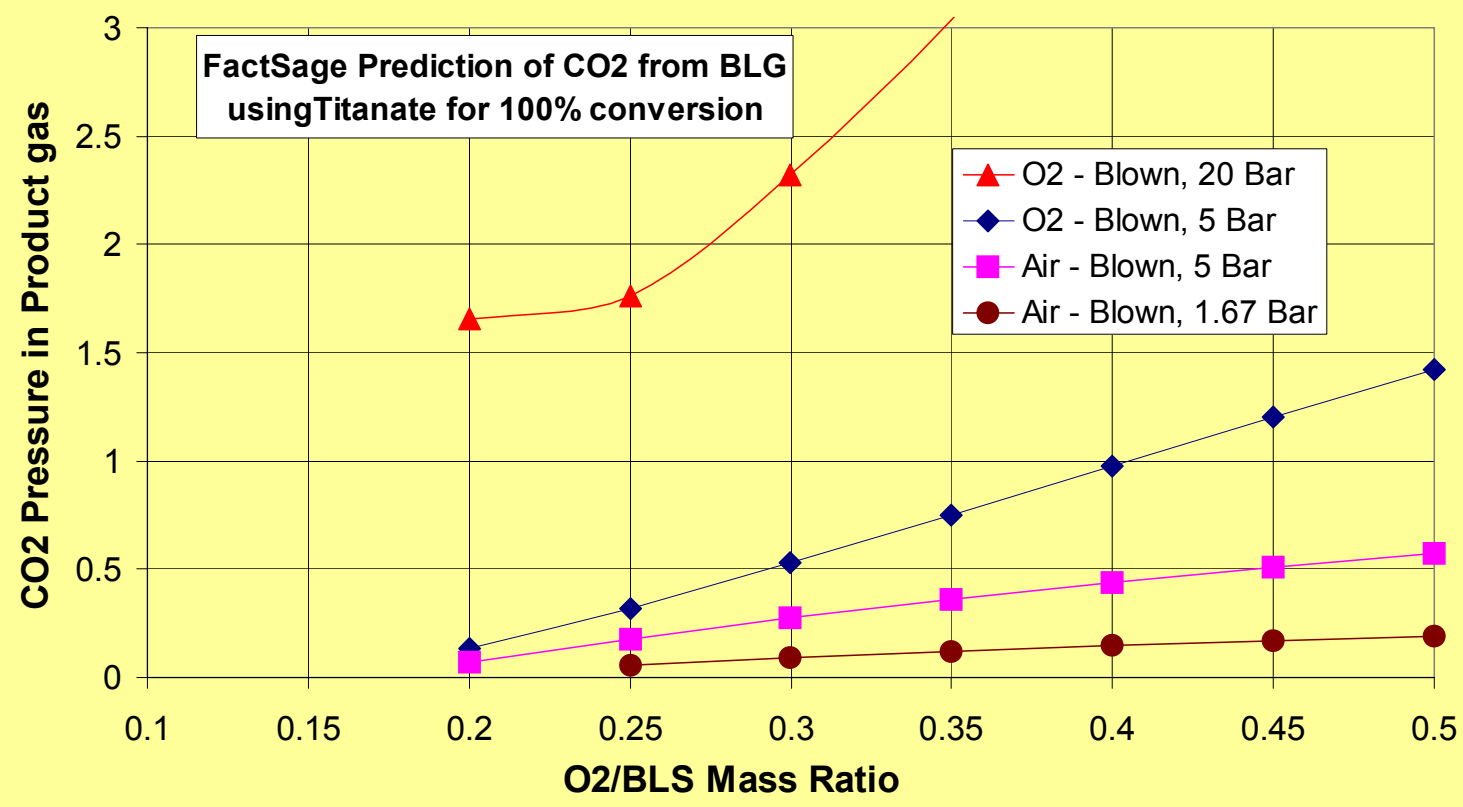

Figure 3. FactSage equilibrium prediction of $\mathrm{CO}_{2}$ concentrations in the product gas for both air- and $\mathrm{O}_{2}$-blown BLG as a function of stoichiometric $\mathrm{O}_{2}$ to fuel ratio (i.e. 1.0 would be stoichiometric combustion)

Using this data it is possible to estimate if the direct causticizing reaction will proceed at industrial conditions by knowing the $\mathrm{CO}_{2}$ level in the product gas. Figure 3 was generated by the FactSage 5.3 equilibrium modeling software. It shows the expected $\mathrm{CO}_{2}$ levels in the syngas as a function of stoichiometric $\mathrm{O}_{2}$ ratio. 0.35 would be a reasonable value for gasification of a biomass. From the experiments, we are looking for conditions where the $\mathrm{CO}_{2}$ level is below about 0.5 bar. At $\mathrm{O}_{2} / \mathrm{BLS}$ of 0.35 , one can see that air-blown BLG up to 5 bars should give acceptable conversion. However the O2blown case at 5 bar would produce a $\mathrm{CO}_{2}$ level around 0.75 bar, which would (using Figure 2) drive the causticizing conversion down to 40-50\%. Decreasing the total pressure using pure $\mathrm{O}_{2}$ would decrease the $\mathrm{CO}_{2}$ and increase the conversion. Clearly though, using $\mathrm{O}_{2}$ at 20 bars would result in a $\mathrm{CO}_{2}$ concentration far too high for any causticizing to take place. Figure 4 shows the results of combining the data in Figure 2 with the modeling in Figure 3. It would be desirable to operate in the $\mathrm{O}_{2}$-blown region to the right in Figure 4, however we need to find a way to limit the $\mathrm{CO}_{2}$ partial pressure to get the higher conversions shown on the left of Figure 4. As stated previously, high pressures are required if $\mathrm{BLG}$ is to be used for efficient combined cycle power generation. In this study we seek to overcome the pressure $/ \mathrm{CO}_{2}$ restriction and achieve direct causticizing at 20 bar. 


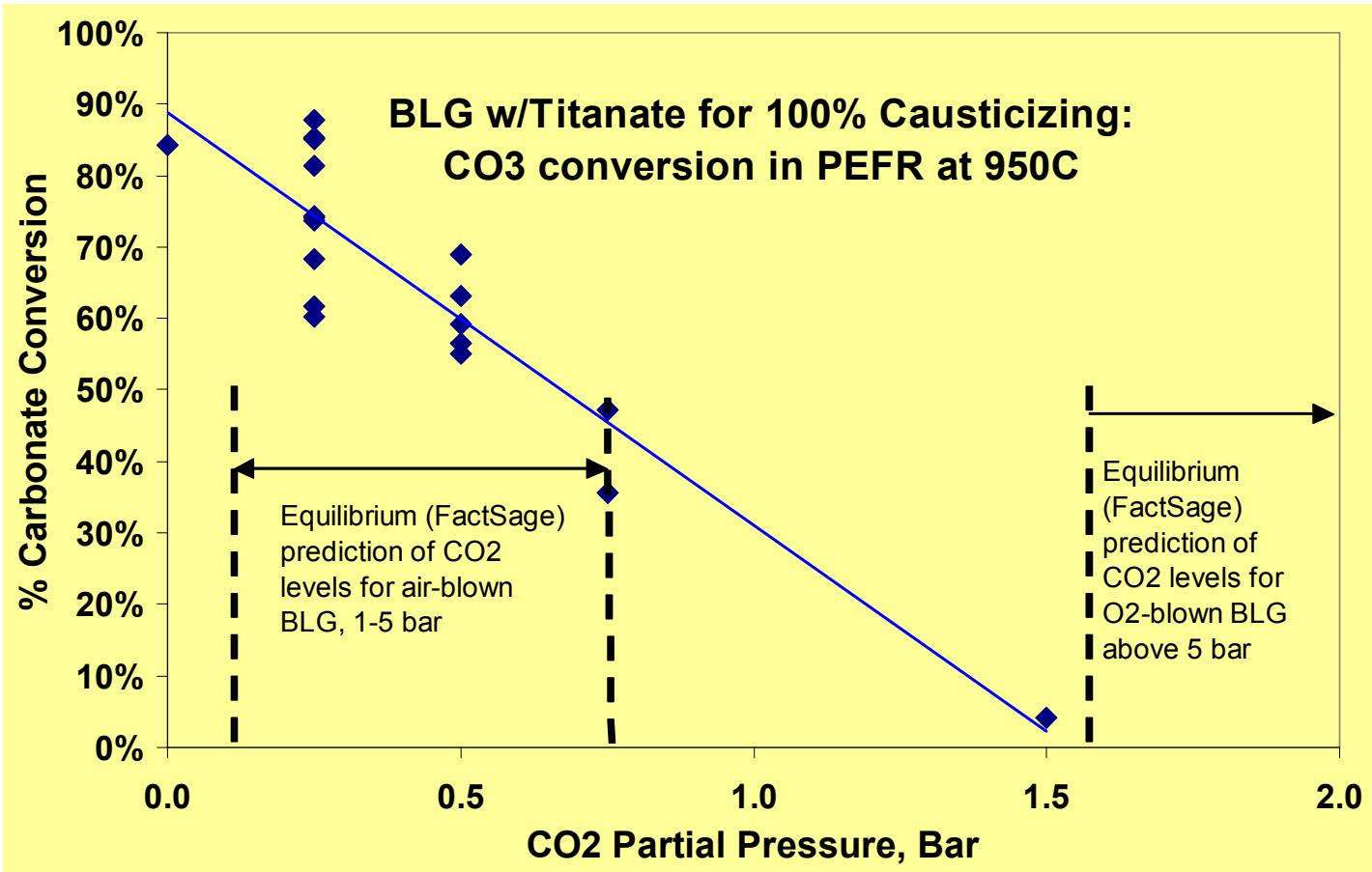

Figure 4. Experimental results of gasifying black liquor with titanate at 5 and 15 total pressure [9]. The conversion of carbonate (i.e. formation of N4T5) decreases with increasing $\mathrm{CO}_{2}$ partial pressure as expected from Reaction (1).

\section{Review of the Project Objectives}

The overall objective is to develop a process that combines black liquor gasification with titanate direct causticizing in a pressurized circulating fluidized bed (CFB) reactor for the purpose of achieving fast gasification kinetics, and in situ causticization, along with the economy of scale benefits of pressurized operation. Note that a CFB (as opposed to entrained-flow) is needed for the added residence time required by lowering the temperature to $850^{\circ} \mathrm{C}$. The original project objectives (in italics) were as follows with discussion included:

Task 1: Verify experimentally that gasification of fixed carbon in a black liquor-titanate mixture proceeds to at least $95 \%$ conversion at conditions suitable for a pressurized CFB configuration: within 8 seconds at 20 bar, and $850 \mathrm{C}$. If $90 \%$ conversion cannot be achieved then a char carbon separation step will be added to the proposed process to recycle unburned carbon back to the gasifier. High carbon conversion was achieved, however it also found to be not as crucial as first thought. The fixed carbon remains with the leached solids and is therefore recycled back the gasifier. Thus the carbon is recycled to extinction.

Task 2: Verify experimentally that once the carbon has been gasified, that the solid phase causticizing reaction will proceed to at least $70 \%$ conversion after the $\mathrm{CO}_{2}-$ containing product gas has been removed from the system. This can also be carried out using the PEFR, customized apparatus in the thermochemical laboratory. If only 50 to $70 \%$ causticizing is obtained then we will have to allow for an extra processing step to 
raise the conversion. This will add to the overall process cost. If at least $50 \%$ conversion cannot be obtained, then the process is probably not viable for combined causticizing and gasification. Sufficiently high conversions were obtained during gasification and leaching. This task was related to an early concept of having a two-stage reactor wherein the $\mathrm{CO} 2$ was removed after the first stage and then the causticizing reactions would proceed further in a second stage.

Task 3: Determine the split of sulfur between the solid and gas phases and identify the consequent limitations on the resulting pulping liquors that can be produced (i.e. which, if any, high yield processes could be employed); also using the PEFR. Note: even if there is no sulfur split, it only means that a straight kraft process will be required. So this is not a critical juncture. The sulfur split was not measured due to limited resources. Early experiments did not produce any causticizing and thus the residence time was increased and the experiments repeated.

Task 4: Develop a viable procedure for leaching the solids to recover the caustic and produce a white liquor at the correct causticity and sulfidity for pulping. Various chemical separation processes such as acidification, complexing, and ion exchange will be considered. If none are found viable, then the fraction of leached NT3/NT6 that must be purged will be calculated based on allowable steady state NPE levels. This will be done in IPST's thermochemical laboratory. The leachate was found to have $\mathrm{pH}$ exceeding that required for white liquor. It can easily be diluted with mill water.

Task 5: Create a process flow sheet, including material and energy balances, of the $C F B$-based BLG recovery island. This task was completed.

Task 6: Perform an economic evaluation of the final process and compare with a Tomlinson-based reference case. If the process economics are deemed promising, then funding will be sought for a pilot phase. This task was completed.

\section{Experimental}

To experimentally evaluate the viability of using titanates for direct causticizing during BLG, NT3 was mixed with black liquor at a ratio sufficient to causticize all of the carbonate remaining in the gasified char (Rxns 1 and 2 above). Raw black liquor was graciously supplied by the Weyerhaeuser Co. Table 2 shows the elemental composition. Assuming complete gasification of hydrocarbons to $\mathrm{H}_{2}$ and $\mathrm{CO}$, and assuming $60 \%$ of the sulfur will partition to the char $\left(40 \%\right.$ to $\left.\mathrm{H}_{2} \mathrm{~S}\right)$, then from the causticizing chemistry in Reactions 1-5, we may calculate the NT3 addition required to convert the char carbonate to hydroxide. It comes to 68 grams NT3 per 100 grams dry black liquor solids. Gasifying this doped liquor with $\mathrm{CO}_{2}$ and $\mathrm{H}_{2} \mathrm{O}$ vapor should lead to formation of a char with no carbonate. Leaching this char (see reactions 3 and 4) should yield a caustic leachate solution with about $0.004 \mathrm{mols}$ of $\mathrm{OH}$ per gram of fixed-carbon-free char.

The NT3 is added to the liquid BL and thoroughly mixed. The mixture was then dried and pulverized, and screened-sieved to 63-90 microns. The BL/NT3 powder was then gasified in IPST's pressurized entrained flow reactor (PEFR) at 850C for approximately 5 seconds. $\mathrm{CO}_{2}$ at varying concentration was used as the oxidizing gas: $5 \%$ and $10 \% \mathrm{CO}_{2}$ in $\mathrm{N}_{2}$ at 5 and 15 bars total pressure. The key variable is the $\mathrm{CO}_{2}$ partial pressure. 
Table 2 .

Weyerhaeuser liquor elemental composition

\begin{tabular}{|c|c|}
\hline $\mathrm{C}$ & $35.1 \%$ (by mass) \\
\hline $\mathrm{H}$ & $3.2 \%$ \\
\hline $\mathrm{O}$ & $34.22 \%$ \\
\hline $\mathrm{N}$ & $0.1 \%$ \\
\hline $\mathrm{Na}$ & $19.6 \%$ \\
\hline $\mathrm{K}$ & $1.14 \%$ \\
\hline $\mathrm{S}$ & $6.47 \%$ \\
\hline $\mathrm{Cl}$ & $0.17 \%$ \\
\hline
\end{tabular}

The pressurized entrained flow reactor (PEFR) is an electrically-heated, laminar flow, drop-tube reactor. Details, schematics, and pictures of the PEFR can be found in Appendix A. It allows for controlled conditions of temperature, residence time, gas composition, and pressure. As the reacted fuel exits the reactor, the solids (char) are collected in a cyclone for subsequent chemical analysis. The gases can be sampled online and/or sampled in gas bags for subsequent analysis. In this work gas analysis was not required. Such reactors have been employed for many years in combustion, gasification, and pyrolysis research. Monson and Germane [22] provide a review of several PEFR's, both in use and mothballed, around the world.

The collected solids (char) from each experiment were leached in water to carry out Reactions (3) and (4). The leachate is then titrated to measure the resulting hydroxide content. This is a measure of both the degree of causticizing and the efficiency of the leaching combined. These results are reported as a function of $\mathrm{CO}_{2}$ partial pressure. Also of concern is the effect of repeated cycling of the titanate. To confirm that the titanates remain active, a batch of liquor/NT3 was gasified, the solids were leached, and the leached solids were mixed with fresh black liquor and gasified again and leached. The amount of hydroxide recovered from the first and second cycles was measured and compared to look for any sort of loss of effectiveness of the titanate.

A material and energy balance (MEB) for a titanate-based recovery process was performed using the Chemcad ${ }^{\circledR}$ process modeling software [22]. Details and assumptions are listed in Appendix C.

The economic analysis includes capital costs for major equipment, and operating costs, to obtain an estimate of the net present value (NPV), and internal rate of return (IRR) for the option of using direct titanate causticization given that a gasifier will be built. The reference case is the BLG cost-benefit analysis performed by Larson [21], which assumes to perform causticizing with an existing lime kiln. The NPV and IRR are then for the use of direct causticizing compared to the base case of BLG with a lime cycle. All assumptions of the analysis can be found in Appendix D 


\section{Results}

\section{The Experiments}

Initially the gasification experiments yielded no hydroxide recovery, presumably because no causticizing took place. These results and conditions are shown in Table 3 . In most cases no hydroxide was recovered from leaching of the char. In some cases, a small fraction of the amount expected was found.

\begin{tabular}{|c|c|c|c|c|}
\hline \multicolumn{5}{|c|}{$\begin{array}{c}\text { Table 3. Results of titration of char produced from } \\
\text { gasification of Ti-doped black liquor. }\end{array}$} \\
\hline Sample ID & Temp, C & $\begin{array}{c}\text { Effective } \\
\text { Length, } \\
\text { mm }\end{array}$ & $\begin{array}{c}\text { Gas Composition } \\
\text { (balance N2) }\end{array}$ & $\begin{array}{c}\text { mols NaOH per } \\
\text { gram char }\end{array}$ \\
\hline P070403A & 850 & 1000 & $5 \% \mathrm{CO} 2,2 \% \mathrm{H} 2 \mathrm{O}$ & $0.00 \mathrm{E}+00$ \\
\hline P070403B & 850 & 1000 & $5 \% \mathrm{CO} 2,2 \% \mathrm{H} 2 \mathrm{O}$ & $0.00 \mathrm{E}+00$ \\
\hline P070411A & 850 & 500 & $5 \% \mathrm{CO} 2,2 \% \mathrm{H} 2 \mathrm{O}$ & $0.00 \mathrm{E}+00$ \\
\hline P070411B & 850 & 500 & $5 \% \mathrm{CO} 2,2 \% \mathrm{H} 2 \mathrm{O}$ & $0.00 \mathrm{E}+00$ \\
\hline P070412A & 850 & 500 & $10 \% \mathrm{CO} 2,2 \% \mathrm{H} 2 \mathrm{O}$ & $0.00 \mathrm{E}+00$ \\
\hline P070412B & 850 & 500 & $10 \% \mathrm{CO} 2,2 \% \mathrm{H} 2 \mathrm{O}$ & $0.00 \mathrm{E}+00$ \\
\hline P070426A & 850 & 2000 & $2 \% \mathrm{H} 2 \mathrm{O}$ & $3.45 \mathrm{E}-04$ \\
\hline P070427A & 850 & 2000 & $1 \% \mathrm{CO} 2,2 \% \mathrm{H} 2 \mathrm{O}$ & $0.00 \mathrm{E}+00$ \\
\hline P070427B & 850 & 2000 & $1 \% \mathrm{CO} 2,2 \% \mathrm{H} 2 \mathrm{O}$ & $0.00 \mathrm{E}+00$ \\
\hline P070502A & 850 & 2000 & $2 \% \mathrm{CO} 2,2 \% \mathrm{H} 2 \mathrm{O}$ & $2.82 \mathrm{E}-04$ \\
\hline P070502C & 850 & 2000 & $5 \% \mathrm{CO} 2,2 \% \mathrm{H} 2 \mathrm{O}$ & $0.00 \mathrm{E}+00$ \\
\hline P070503A & 850 & 2000 & $10 \% \mathrm{CO} 2,2 \% \mathrm{H} 2 \mathrm{O}$ & $0.00 \mathrm{E}+00$ \\
\hline P070503B & 850 & 2000 & $10 \% \mathrm{CO} 2,2 \% \mathrm{H} 2 \mathrm{O}$ & $0.00 \mathrm{E}+00$ \\
\hline P070503C & 850 & 2000 & $5 \% \mathrm{CO} 2,2 \% \mathrm{H} 2 \mathrm{O}$ & $0.00 \mathrm{E}+00$ \\
\hline P070503D & 850 & 2000 & $2 \% \mathrm{CO} 2,2 \% \mathrm{H} 2 \mathrm{O}$ & $2.96 \mathrm{E}-04$ \\
\hline P070503E & 850 & 2000 & $2 \% \mathrm{H} 2 \mathrm{O}$ & $3.30 \mathrm{E}-04$ \\
\hline
\end{tabular}

We know that under conditions similar to those of Table 3 , but at $950^{\circ} \mathrm{C}$, causticizing was achieved [9]. We can reasonably assume that at $850^{\circ} \mathrm{C}$ the causticizing kinetics are slower than at $950^{\circ} \mathrm{C}$, and perhaps the short time in the PEFR (1.5 to 5 seconds in Table 3) was not enough for Reaction (1) to take place. Residence times were therefore increased to approximately 8 seconds. The $\mathrm{CO}_{2}$ gas composition was varied from 1-5\% with 5 bar total pressure, and fixed $2 \% \mathrm{H}_{2} \mathrm{O}$.

The results at longer residence times are shown in Figure 5. Allowing more time for kinetics was successful. The shape of Figure $5\left(850^{\circ} \mathrm{C}\right)$ is similar to the previous results shown in Figure $4\left(950^{\circ} \mathrm{C}\right)$. In Figure 5 we have used mols of hydroxide recovered on the Y-axis as opposed to carbonate conversion. This reflects the combining of the causticizing reaction ( $\mathrm{Rxn} 1)$ with the leaching reaction ( $\mathrm{Rxn} 3$ ). Note that the stoichiometric maximum in Figure 5 is 0.004 mols $\mathrm{OH}$ per gram char. Values below that level would indicate the sum of incomplete causticizing and incomplete leaching. Note also that Figure 5 represents first pass results only. That is there is no NT6 present. On subsequent cycling, Reactions (2) and (4) will also take place, thus increasing the hydroxide recovered at any given value of $\mathrm{CO}_{2}$ partial pressure. 


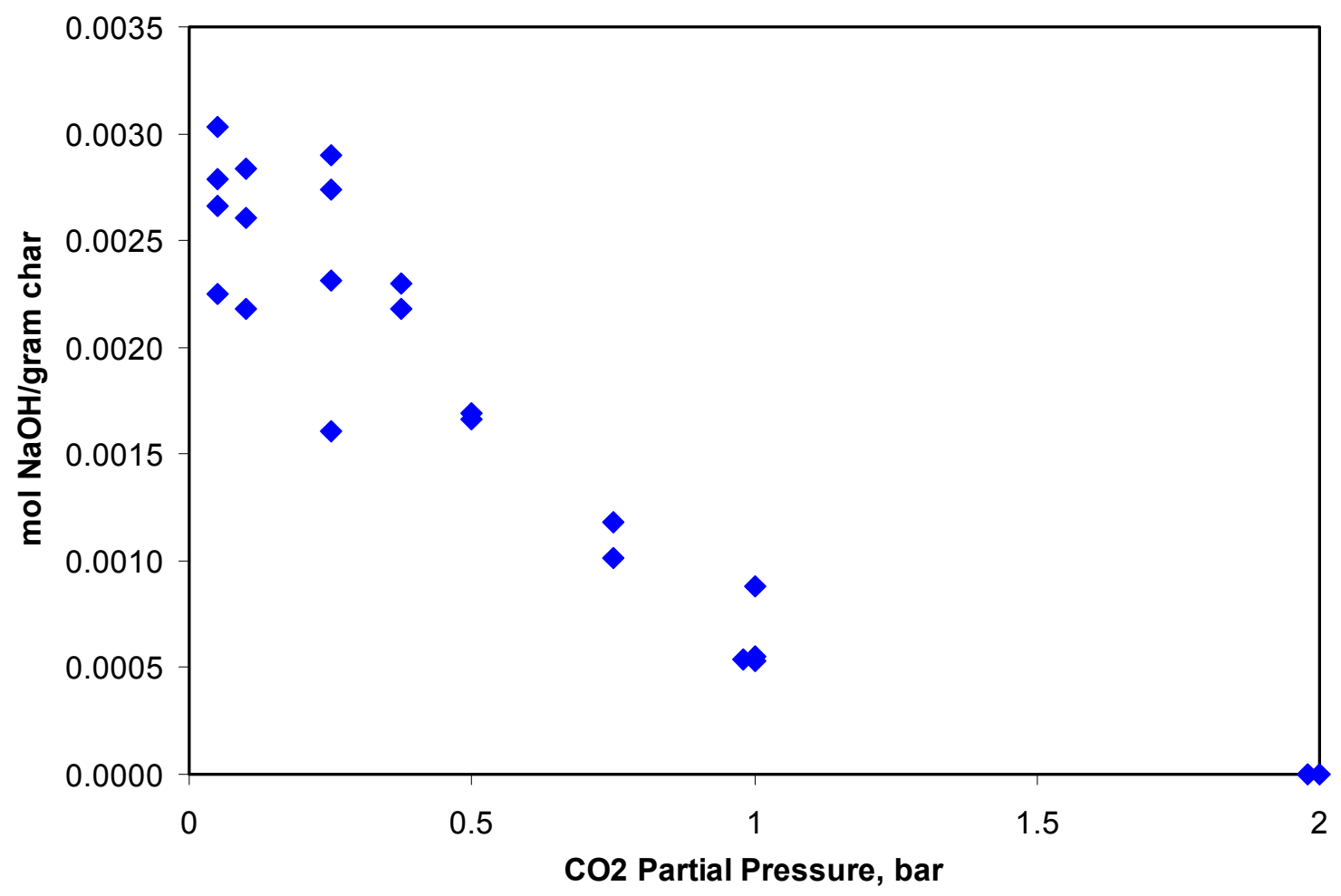

Figure 5. Hydroxide recovered from char formed by gasifying black liquor doped with $0.68 \mathrm{~g} \mathrm{NT} 3 / \mathrm{g}$ dry BL solids at $850^{\circ} \mathrm{C}$ at varying $\mathrm{CO}_{2}$ partial pressures. At this doping level the theoretical maximum hydroxide recovered would be 0.004 mols $\mathrm{OH}$ per gram char on carbon-free basis. Fixed carbon content was not measured. Data points shown are mols $\mathrm{OH}$ per gram char including fixed carbon.

As before, Figure 5 shows that the $\mathrm{CO}_{2}$ partial pressure should be kept below about 0.5 bar to achieve reasonable conversion, and the lower the better. Thus if the gasifier pressure is 10 bar, then the desired $\mathrm{CO}_{2}$ concentration should be below 5\%. At 20 bar, it should be below 2.5\%. Any solution to this limitation will require considerable manipulation of the gas composition. If enough oxygen is fed to gasify all of the fixed carbon, then we can expect much higher $\mathrm{CO}_{2}$ levels in the syngas. On solution is to operate at very low $\mathrm{O}_{2} /$ fuel ratios, thus favoring the formation of $\mathrm{H}_{2}, \mathrm{CO}$, and light hydrocarbons, over $\mathrm{CO}_{2}$ and $\mathrm{H}_{2} \mathrm{O}$. The problem with this approach is that little heat is released and the gasifier can only operate at lower temperatures. Another approach would be to separate the syngas from the solids leaving the gasifier and allow the solids to continue the causticizing reactions in a second reactor. However, since the causticizing reactions release pure $\mathrm{CO}_{2}$, the partial pressure of $\mathrm{CO}_{2}$ would be near the reactor pressure and the result would likely be reversal of the reactions. Still another approach might be to artificially manipulate the syngas composition within the gasifier. This subject will be discussed further in the next section. 
Another important consideration is whether the leached solids are still reactive during subsequent recycling. Thus far in this project, we have used fresh NT3 to mix with black liquor and then gasify the mixture. It does not account for any sort of loss of reactivity of the titanates, nor does it allow for the formation of NT6 (i.e. Rxns 2 and 4). In a full scale system, the leached solids would be recycled and mixed with incoming black liquor and fed to the gasifier. To confirm reactivity of the solids, a sample of black liquor doped with $0.68 \mathrm{~g}$ NT3/gDBLS was pyrolyzed in $\mathrm{N}_{2}$ at $850 \mathrm{C}$. The chart was then leached to recover hydroxide and convert the N4T5 back to NT3 and NT6. The NT3/NT6 was then mixed with fresh black liquor, dried, and ground in jar mill. This mix of fresh liquor and once-used titanate was then pyrolyzed again at $850 \mathrm{C}$, and leached to measure the hydroxide recovered on the second "pass." The results are shown above in Table 4.

In the first experiment on reactivity or leached solids, the hydroxide recovery increased somewhat from 0.00432 to $0.00494 \mathrm{~mol} \mathrm{NaOH}$ per gram BLS. This is to be expected since NT3 would have been the only form of titanate in the first pass, whereas some NT6 would form during leaching and be present in the second pass. The second experiment yielded only $0.0038 \mathrm{~mol} \mathrm{NaOH}$ per gram BLS. Obviously much more data would need to be taken to confirm the stability of recycling the NT3. However these experiments confirm significant activity remains after a first pass through the gasifier, indicating that the process remains viable. A separate study would be in order to confirm the effects of several repeated cycles.

\begin{tabular}{|c|c|c|}
\hline Experiment & $\begin{array}{l}\text { Mols NaOH formed/gram } \\
\text { DBLS }\end{array}$ & Average \\
\hline $\begin{array}{l}1^{\text {st }} \text { pass black liquor with } 0.68 \mathrm{~g} \\
\text { NT3/gDBLS (reference). }\end{array}$ & 0.00442 & \multirow[t]{2}{*}{0.00432} \\
\hline Replicate leaching of $1^{\text {st }}$ pass. & 0.00421 & \\
\hline $\begin{array}{l}\text { Expt } \# 080515,2^{\text {nd }} \text { pass, black liquor } \\
\text { with } 0.68 \mathrm{~g} \text { of leached solids/gDBLS. }\end{array}$ & 0.00499 & \multirow[t]{2}{*}{0.00494} \\
\hline Expt $\# 080515$, replicate leaching. & 0.00488 & \\
\hline $\begin{array}{l}\text { Expt } \# 080721,2^{\text {nd }} \text { pass replicate } \\
\text { conditions. }\end{array}$ & 0.0038 & 0.0038 \\
\hline
\end{tabular}




\section{The Material and Energy Balance}

The MEB was done using the Chemstations $\mathrm{ChemCad}^{\circledR}$ (version 6.1.4) process modeling software. We have shown experimentally that the causticizing chemistry works in situ during BLG at the temperature of interest $\left(850^{\circ} \mathrm{C}\right)$. This result was expected given the previous results at $950^{\circ} \mathrm{C}$. The crucial objective of this project was to devise a way to maintain the $\mathrm{CO}_{2}$ partial pressure below 0.5 bar, while operating the gasifier at 20 bars (where the expected $\mathrm{CO}_{2}$ partial pressure would be about 3-4 bar). We propose to manipulate the water-gas shift (WGS) reaction to convert as $\mathrm{CO}_{2}$ to $\mathrm{CO}$ as possible.

The raw syngas in the gasifier, as in any gasification system, is rich in $\mathrm{H}_{2}, \mathrm{CO}$, and light hydrocarbons, as well as water vapor and $\mathrm{CO}_{2}$. It is the $\mathrm{CO}_{2}$ concentration in the gasifier that we wish to minimize. The water-gas shift (6) and Boudouard (7) reactions below govern the product gas distribution from a gasfier. By adding hydrogen to the syngas, reaction (6) is pushed to the left and thus the partial pressure of $\mathrm{CO}_{2}$ is decreased. Reaction (7) becomes relevant at low $\mathrm{O}_{2}$ /fuel ratios where there is excess carbon. Operating at low $\mathrm{O}_{2} /$ fuel ratios will tend to form less $\mathrm{CO}_{2}$ which is our goal.

$$
\begin{gathered}
\mathrm{CO}+\mathrm{H}_{2} \mathrm{O} \leftrightarrow \mathrm{CO}_{2}+\mathrm{H}_{2} \\
\mathrm{C}+\mathrm{CO}_{2} \leftrightarrow 2 \mathrm{CO}
\end{gathered}
$$

Rather than purchasing $\mathrm{H}_{2}$ to add to the gasifier, it can easily be separated from the syngas with a membrane and recycled. Since the recycled $\mathrm{H}_{2}$ simply circulates, it is possible to use a large membrane and use a high $\mathrm{H}_{2}$ recycle ratio, thus driving reaction (6) far to the left. All of this assumes that enough $\mathrm{O}_{2}$ is used to generate enough to heat for the system to reach $850^{\circ} \mathrm{C}$. In addition, reaction (7) can be used to inhibit $\mathrm{CO}_{2}$ formation by maintaining a small amount of char carbon in the bed solids (if possible). We have already determined that char carbon does not impact leaching of the N4T5 solids and that the carbon remains bound with the NT3 leaving the leacher. However we will have to verify experimentally that char carbon entering with the NT3 does not interfere with the causticizing reactions during gasification. A process simulator such as $\mathrm{ChemCad}^{\mathrm{TM}}$ is ideal (and expedient) to perform the iterative calculations to determine if all the necessary constraints can be met:

1. At 20 bar the $\mathrm{CO}_{2}$ level remains below 0.5 bar (est) to allow in situ causticizing.

2. The heat released from partial oxidation must be sufficient to maintain $850^{\circ} \mathrm{C}$.

3. Whether the required recycle ratios of $\mathrm{H}_{2}$ and char carbon are within reason.

Figure 6 shows the proposed process for recycling $\mathrm{H}_{2}$ back to the gasifier to shift the water-gas-shift reaction ( $\mathrm{Rxn} 6$ ) the left and thus minimize the $\mathrm{CO}_{2}$ partial pressure. We use the ChemCad ${ }^{\text {TM }}$ simulator to estimate if there is enough $\mathrm{H}_{2}$ to force the $\mathrm{CO}_{2}$ partial pressure below 0.5 bar. The variables available to manipulate in Figure 6 in order to satisfy the three constraints are $\mathrm{O}_{2}$ and water flow rates, the fraction of $\mathrm{H}_{2}$ returned to the gasifier, and the fraction of the titanate solids that are diverted to the NPE washer. 


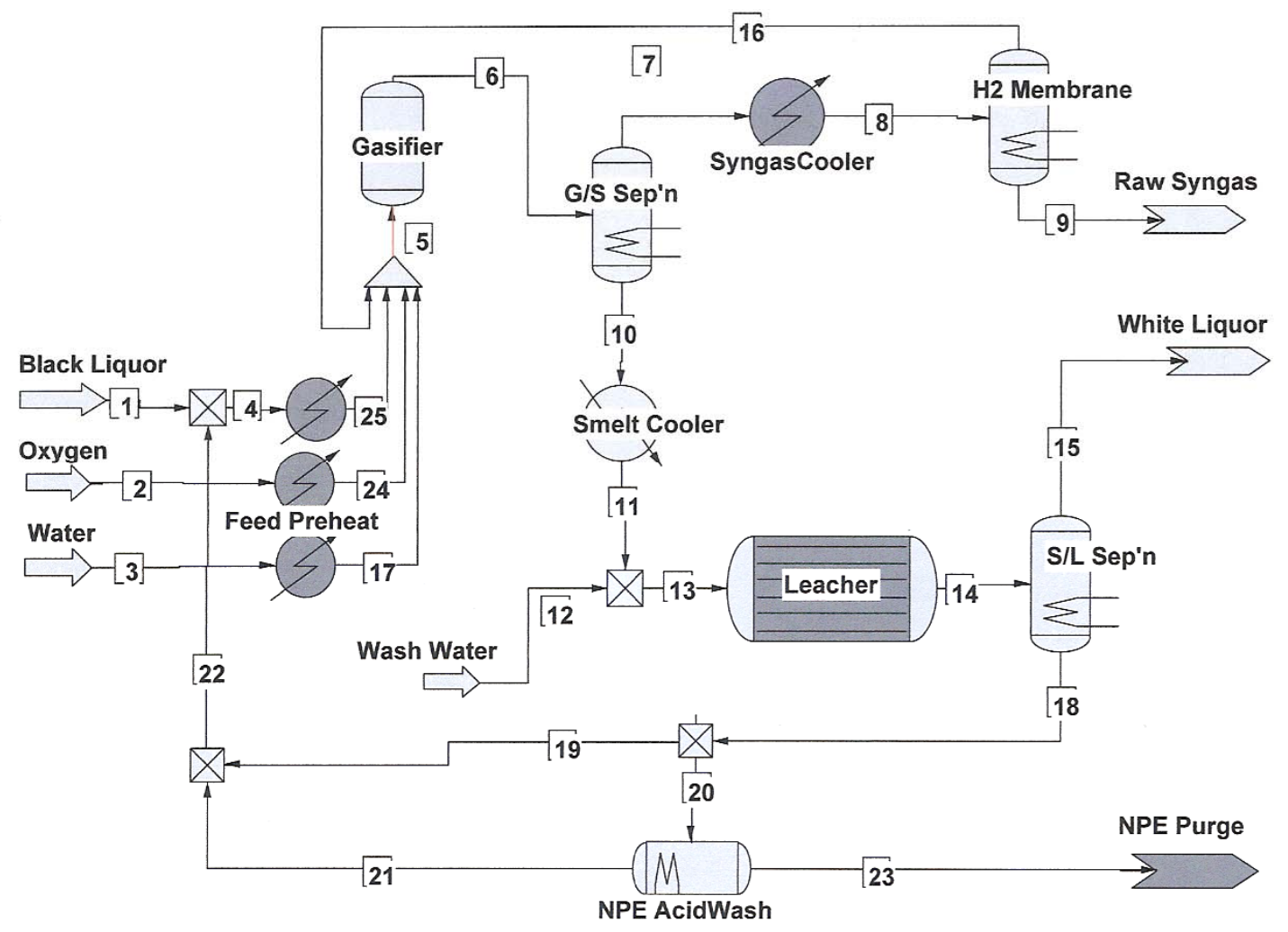

Figure 6. Proposed process for pressurized BLG with titanate direct causticizing. Hydrogen is recycled to affect the water-gas-shift reaction to reduce carbon dioxide.

In the proposed process shown in Figure 6, the inputs include the concentrated black liquor from the evaporators, as well as oxygen and water (to the steam generator). The leached titanate solids are mixed with the liquor and heated to $200^{\circ} \mathrm{C}$ prior to feeding into the gasifier. A membrane is used to separate a large fraction of the $\mathrm{H}_{2}$ from the product gas and recycle it back the gasifier; the exact fraction being a control variable. In the gasifier the organic portion of the liquor is gasified into syngas, and the causticizing reactions take place. The syngas is cooled to $200^{\circ} \mathrm{C}$ prior to membrane separation. The raw syngas after removal of most of the $\mathrm{H}_{2}$ would require further cleaning (i.e. $\mathrm{H}_{2} \mathrm{~S}$ removal, etc.) before use in a turbine, or Fischer-Tropsh plant. The solids (aka smelt) will require cooling which could be as simple as quenching in the leacher with some form of indirect cooling. Following the leaching reactions, the [now caustic] leachate (i.e. liquid phase) becomes the white liquor. It may require some small $\mathrm{pH}$ adjustment (not shown) but calculations show that the leaching reactions will take place at $\mathrm{pH}$ levels sufficient to produce a suitable white liquor. The leached solids (NT3) are then recycled back to be mixed with incoming black liquor. A fraction of the solids are diverted to an acid washer to dissolve and remove the non-process elements (NPE's). The flow rates of some of the key streams are shown in Table 5. 
Table 5

Key Flow Rates for Figure 6 (in $\mathrm{Kg} / \mathrm{hr}$ )

\begin{tabular}{|c|c|c|c|c|c|c|c|c|c|c|c|c|c|c|c|c|c|}
\hline Steam \# & 1 & 2 & 3 & 5 & 6 & 8 & 9 & 10 & 12 & 15 & 16 & 17 & 18 & 21 & 23 & 24 & 25 \\
\hline Steam Name & $\begin{array}{l}\text { Black } \\
\text { Liquor }\end{array}$ & Oxygen & Water & $\begin{array}{l}\text { Gasifier } \\
\text { Feed }\end{array}$ & $\begin{array}{l}\text { Gasifier } \\
\text { Effluent }\end{array}$ & $\begin{array}{l}\text { Cooled } \\
\text { Syngas }\end{array}$ & $\begin{array}{l}\text { Raw } \\
\text { Syngas }\end{array}$ & Smelt & $\begin{array}{l}\text { Wash } \\
\text { Water }\end{array}$ & $\begin{array}{l}\text { White } \\
\text { Liquor }\end{array}$ & $\begin{array}{l}\mathrm{H} 2 \\
\text { Recycle }\end{array}$ & $\begin{array}{l}\text { Steam } \\
500 \mathrm{C}\end{array}$ & $\begin{array}{l}\text { Leached } \\
\text { Solids }\end{array}$ & $\begin{array}{l}\text { Washed } \\
\text { Solids }\end{array}$ & \begin{tabular}{|l} 
NPE \\
Purge \\
\end{tabular} & $\mathrm{O} 2$ & $\begin{array}{l}\text { Ti-Doped } \\
\text { Liquor }\end{array}$ \\
\hline Temp, C & 90 & 25 & 50 & 182 & 857 & 200 & 200 & 857 & 30 & 200 & 200 & 500 & 200 & 200 & \begin{tabular}{|l}
200 \\
\end{tabular} & 500 & 200 \\
\hline Pressure, bar & 20 & 20 & 20 & 20 & 20 & 20 & 20 & 20 & 20 & 20 & 20 & 20 & 20 & 20 & 20 & 20 & 20 \\
\hline Total flow, Kg/hr & 114232 & 68000 & 500 & 262566 & 262540 & 187145 & 153057 & 75395 & 25000 & 55515 & 34088 & 1500 & 45881 & 6597 & 135 & 68000 & 158978 \\
\hline $\begin{array}{l}\text { Black Liquor Organics, } \\
\mathrm{Kg} / \mathrm{hr}\end{array}$ & 50418 & 0 & 0 & 50418 & Soloto & (c.ing & . & 0 & 0 & 0 & 0 & 0 & 0 & 0 & 0 & 0 & 50418 \\
\hline Water, Kg/hr & 20486 & 0 & 500 & 22997 & 38093 & 38093 & 38093 & 0 & 25000 & 19213 & 0 & 1500 & 2011 & 152 & 0 & 0 & 21497 \\
\hline Hydrogen & 0 & 0 & 0 & 34088 & 35882 & 35882 & 1794 & 0 & 0 & 0 & 34088 & 0 & 0 & 0 & 0 & 0 & 0 \\
\hline Carbon Monoxide & 0 & 0 & 0 & 0 & 58596 & 58596 & 58596 & 0 & 0 & 0 & 0 & 0 & 0 & 0 & 0 & 0 & 0 \\
\hline Carbon Dioxide & 0 & 0 & 0 & 0 & 48546 & 48546 & 48546 & 0 & 0 & 0 & 0 & 0 & 0 & 0 & 0 & 0 & 0 \\
\hline Nitrogen & 0 & 6028 & 0 & 6028 & 6028 & 6028 & 6028 & 0 & 0 & 0 & 0 & 0 & 0 & 0 & 0 & 6028 & 0 \\
\hline Oxygen & 0 & 61972 & 0 & 61972 & 0 & 0 & 0 & 0 & 0 & 0 & 0 & 0 & 0 & 0 & 0 & 61972 & 0 \\
\hline Hydrogen Sulfide & 0 & 0 & 0 & 0 & 0 & 0 & 0 & 0 & 0 & 0 & 0 & 0 & 0 & 0 & 0 & 0 & 0 \\
\hline Sodium Carbonate & 32484 & 0 & 0 & 32484 & 4384 & 0 & 0 & 4384 & 0 & 4384 & 0 & 0 & 0 & 0 & 0 & 0 & 32484 \\
\hline Sodium Sulfide & 10386 & 0 & 0 & 10386 & 10386 & 0 & 0 & 10386 & 0 & 10386 & 0 & 0 & 0 & 0 & 0 & 0 & 10386 \\
\hline Sodium Chloride & 323 & 0 & 0 & 323 & 323 & 0 & 0 & 323 & 0 & 323 & 0 & 0 & 0 & 0 & 0 & 0 & 323 \\
\hline$(\mathrm{Na} 2 \mathrm{O})(\mathrm{TiO} 2) 3$ & 0 & 0 & 0 & 15377 & 0 & 0 & 0 & 0 & 0 & 0 & 0 & 0 & 15377 & 2307 & 0 & 0 & 15377 \\
\hline$(\mathrm{Na} 2 \mathrm{O})(\mathrm{TiO} 2) 6$ & 0 & 0 & 0 & 27595 & 0 & 0 & 0 & 0 & 0 & 0 & 0 & 0 & 27595 & 4139 & 0 & 0 & 27595 \\
\hline$(\mathrm{Na} 2 \mathrm{O}) 4(\mathrm{TiO} 2) 5$ & 0 & 0 & 0 & 0 & 59404 & 0 & 0 & 59404 & 0 & 0 & 0 & 0 & 0 & 0 & 0 & 0 & 0 \\
\hline Sodium Hydroxide & 0 & 0 & 0 & 0 & 0 & 0 & 0 & 0 & 0 & 0 & 0 & 0 & 0 & 21208 & 21208 & 0 & 0 \\
\hline NPE's & 135 & 0 & 0 & 897 & 897 & 897 & 0 & 0 & 0 & 897 & 897 & 0 & 897 & 897 & 0 & 0 & 0 \\
\hline
\end{tabular}


Table 5 shows many of the key flow rates and stream temperatures of the process shown in Figure 6. Detailed data for all streams are included in the appendices. From this we can already see that the temperature within the gasifier is $857^{\circ} \mathrm{C}$ which satisfies one of the criteria. The gas composition of stream 6 leaving the gasifier (and within the gasifier) is shown in Table 6 . As we can see the ChemCad ${ }^{\circledR}$ simulation calculates the $\mathrm{CO}_{2}$ volume content to be $4.7 \%$. At 20 bar total pressure this translates to about 0.9 bar partial $\mathrm{CO}_{2}$ pressure, which is greater than the desired value of 0.5 bar. Reading from Figure 5, the expected hydroxide recovery would only be about $0.001 \mathrm{~mol} \mathrm{NaOH} / \mathrm{gram}$ char which is a third of the maximum measured value of $0.003 \mathrm{~mol} / \mathrm{gram}$ char. This would require that more titanate be circulated and would thus reduce the gasifier temperature. It is likely that a true optimization of the process model of Figure 6, would result in a lower $\mathrm{CO}_{2}$ pressure in the gasifier. Another alternative is to lower the pressure to 10 bars total, which would give 0.47 bar $\mathrm{CO}_{2}$ pressure, which would meet the criteria. One could also decrease the amount of water entering the system, or increase the recycle ratio; either of which would further push the WGS reaction further away from $\mathrm{CO}_{2}$ formation. The variables in this model were manipulated manually (trial and error) to get close to a working solution. No mathematical optimization was performed. Additional work would likely yield a higher pressure solution.

Table 6

Gas Composition Leaving Gasifier (Stream 6) in Figure 6

(in $\mathrm{mol} \%$ )

\begin{tabular}{|l|r|}
\hline Hydrogen & $76.3 \%$ \\
\hline Carbon Monoxide & $9.0 \%$ \\
\hline Carbon Dioxide & $4.7 \%$ \\
\hline Nitrogen & $0.9 \%$ \\
\hline Oxygen & $0.0 \%$ \\
\hline Hydrogen Sulfide & $0.0 \%$ \\
\hline Water & $9.1 \%$ \\
\hline Ammonia & $0.04 \%$ \\
\hline
\end{tabular}

Table 7.

Process Data from Figure 6.

\begin{tabular}{|l|l|}
\hline $\mathrm{H} 2$ recycle ratio at membrane & 0.95 \\
\hline Oxygen /Nitrogen composition & $90 \% / 10 \%$ \\
\hline Leached solids diverted to wash & $15 \%$ \\
\hline Black liquor feed rate & $114,232 \mathrm{Kg} / \mathrm{hr}$ \\
\hline Black liquor preheat (to $200^{\circ} \mathrm{C}$ ) load & $20,000 \mathrm{MJ} / \mathrm{hr}$ \\
\hline Oxygen preheating & $32,000 \mathrm{MJ} / \mathrm{hr}$ \\
\hline Steam preheating & $4770 \mathrm{MJ} / \mathrm{hr}$ \\
\hline Smelt cooling & $-87,900 \mathrm{MJ} / \mathrm{hr}$ \\
\hline Syngas cooling & $-487,000 \mathrm{MJ} / \mathrm{hr}$ \\
\hline Fixed carbon leaving gasifier & zero \\
\hline
\end{tabular}


Additional key process data and specifications for Figure 6 are shown in Table 7. The heat losses due to cooling are substantial. Much of heat could be recovered to provide both the required process feed heating, and steam generation for the mill. Again, no optimization was performed as this project was limited to the direct causticizing aspect. The complete set of process data for Figure 6 as well as the ChemCad ${ }^{\circledR}$ model $^{\circ}$ assumptions can be found in Appendix C. Also noteworthy in Table 7 is the absence of $\mathrm{H}_{2} \mathrm{~S}$ in all of the streams. This is because the reactions to form $\mathrm{H}_{2} \mathrm{~S}$ from $\mathrm{Na}_{2} \mathrm{~S}$ in the gasifier were inadvertently omitted. We would have to assume that $60 \%$ of the sulfur would partition to the smelt phase but in the current model, all of it leaves with the smelt and leaches into the white liquor.

\section{The Cost-Benefit Analysis}

The economic analysis employs the same cost model used in Sinquefield and Cantrell [9]. In that project a titanate leaching system consisting of three leaching stages and an acid wash system for NPE removal was modeled to estimate the internal rate of return (IRR), and the net present value (NPV). The model utilized an extensive database of equipment prices to produce a $+/-30 \%$ capital cost. For the process shown in Figure 6, we have one leaching stage, an acid wash system for NPE's, and a membrane separator for hydrogen recycle. The cost model in [9] can easily be adjusted (see appendix D for details):

- Add \$3MM to 'major equipment' for the membrane gas separator.

- Reduce the $\$ 9.5 \mathrm{MM}$ cost of the leaching system agitators and pumps [9] by $60 \%$ to correct for one leaching stage versus three leaching stages in [9].

- Correct the TCC from 2006 to current price. The Chem Engr Plant cost index for Sept 2006 was 513, and for Sept. 2009 was 525.7

- Assume other construction direct and indirect costs are close enough to use for this study.

The details of the cost model can be found in Appendix D. Note that what we are modeling is the NPV and IRR of the titanate causticizing system instead of a lime cycle. The gasifier is already assumed to be being built and therefore not included. The lime is also assumed to already exist. The results are shown in Table 8 . The savings of the titanate system is largely due to the saving in energy (fuel oil or natural gas) to fire the lime kiln. Therefore we have shown the results for a number of values of energy cost.

Table 8. NPV and IRR as a Function of Fuel Cost

\begin{tabular}{|c|c|c|}
\hline \$MMBtu displaced (i.e. oil or NG price) & NPV, \$MM & IRR, $\%$ \\
\hline$\$ 6 /$ MBtu & $\$(6.6)$ & $4.5 \%$ \\
\hline$\$ 8$ & $\$ 10.6$ & $16.8 \%$ \\
\hline$\$ 10$ & $\$ 27.8$ & $26.7 \%$ \\
\hline$\$ 12$ & $\$ 45.0$ & $36.3 \%$ \\
\hline$\$ 14$ & $\$ 62.2$ & $46.3 \%$ \\
\hline
\end{tabular}


The proposed system is therefore more favorable at higher energy prices. At $\$ 10 / \mathrm{MMBtu}$ or higher, the system is economically attractive, and becomes very attractive as the price of fuel increases.

\section{Conclusions}

We have shown experimentally and through process modeling that the titanate direct causticizing chemistry for pressurized BLG is feasible up to at least 10 bars pressure at $850^{\circ} \mathrm{C}$. 10 bars did not meet our goal of 20 bars. No optimization was done due to limited resources and scope. With process optimization the total pressure could likely be increased somewhat. There is also the possibility of adding additional hydrogen to further affect the WGS reaction and further inhibit $\mathrm{CO}_{2}$ formation and thus allow the total pressure to be raised above 10 bar.

As expected the $\mathrm{CO}_{2}$ partial pressure is the factor limiting the pressure. If the reactor temperature were further lowered to $750^{\circ} \mathrm{C}$, the oxygen demand would correspondingly decrease as would the $\mathrm{CO}_{2}$. It is possible some fixed carbon would circulate with the solids and further decrease the $\mathrm{CO}_{2}$ level via the Boudouard reaction (which did not play a role at $850^{\circ} \mathrm{C}$ ). Any reduction in $\mathrm{CO}_{2}$ pressure would allow the causticizing chemistry to work at higher total system pressures. The lower temperature would also slow the kinetics and thus require a longer residence time. A large circulating fluid bed reactor would be the preferred type to achieve the required residence times.

Additionally we have shown that the concept of separating hydrogen and recycling it back the gasifier can drastically shift the WGS reaction and significantly reduce the $\mathrm{CO}_{2}$ concentration in the syngas. This has application beyond the titanate causticizing process. It can be used to manipulate the $\mathrm{H}_{2} / \mathrm{CO}$ ratio in Fischer-Tropsh and other syngas to chemicals processes.

The process economics are favorable for the BLG with titanate causticizing as long as fuel (for heat) costs are above about $\$ 8$ to $\$ 10 / \mathrm{MMBtu}$. While energy prices fluctuate, the long-term trend is to increase. Therefore novel processes with increased efficiencies must be considered for the industry to remain competitive.

\section{Future Work}

Additional work in this area would include optimizing the process to further reduce $\mathrm{CO}_{2}$ partial pressure. This would allow higher total system pressures. Lowering the temperature to $750^{\circ} \mathrm{C}$ should definitely be investigated given the improvements found by going from $950^{\circ} \mathrm{C}$ to $850^{\circ} \mathrm{C}$. While it is not mandatory to gasify black liquor at 20 bar or higher, the higher pressures results in smaller pressure vessels and better process economics. Also when the syngas is already pressurized it can be cleaned hot (or at least warm) and fed directly to a gas turbine without cooling to typical scrubbing temperatures and then recompressing it. F-T processes are typically carried out at 50-100 bar so 10 bar versus 20 in this system will not appreciably affect the viability.

[Continued over] 
We will also research further applications of recycling hydrogen for manipulation of the WGS reaction. Lastly, a pilot black liquor gasifier with titanate recovery system and hydrogen recycle could be built to verify the process model.

\section{Acknowledgements}

This work was performed under a grant from the U.S. Dept. of Energy, with matching funds from the Weyerhaeuser Co., Georgia Pacific, and the State of Georgia. We gratefully acknowledge their support.

\section{References}

[1] Tucker, P., et.al., "Closing in on a Step Change in Power Generation from SelfGenerated Fuels — The Pathway Parts 1 and 2", TAPPI Solutions, Jan \& Feb, 2002

[2] Nohlgren, I., PhD Thesis, Lulea University, Sweden, 2002

[3] Nohlgren, I., Sricharoenchaikul, V., Sinquefield, S., Frederick, W., Theliander, H., "Black Liquor Gasification with Direct Causticization Using Titanates in a Pressurized Entrained-Flow Reactor Part 1: Kinetics of the Causticization Reaction”, J. Pulp Pap. Sci., 2003, 29(4), 107-113

[4] Magnusson, K., "The Recycling Effects on the Solid Sodium Titanate process", M.S. Thesis, Chalmers University, Sweden, 2003

[5] Dahlquist, E., Jones, A., "Presentation of a Dry Black Liquor Gasification Process with Direct Causticization", TAPPI J., 4(5), 2005

[6] Nohlgren, I., Sricharoenchaikul, V., Sinquefield, S., Frederick, W., Theliander, H., "Black Liquor Gasification with Direct Causticization Using Titanates in a Pressurized Entrained-Flow Reactor Part 2: Carbon and Carbon Species Transitions", J. Pulp Pap. Sci., 2003, 29(10).

[7] Nohlgren, I., Sricharoenchaikul, V., Sinquefield, S., Frederick, W., Theliander, H., "Black Liquor Gasification with Direct Causticization using Titanates in a Pressurized Entrained-Flow Reactor, Part 3: Sulfur and Sulfur Species Transitions”, J. Pulp Pap. Sci., 2004.

[8] Minutes of IEA Annex XV Meeting on Black Liquor and Biomass Gasification in Turku, Finland, August 30 - September 1, 2004

[9] Sinquefield, S.A, Cantrell, J., Zeng, X., Ball, A., Empie, H.J. "Causticizing for Black Liquor Gasifiers”, U.S. DOE project DE-FC26-02NT41492, Oct. 2007.

[11] Zou, X., "Recovery of Kraft Black Liquor Including Direct Causticization", Ph. D. Thesis, McGill University, Montreal, QC, Canada (1991).

[12] Nohlgren, I., Theliander, H., Zhuang, Q. and Van Heiningen, A.R.P, "Model Study of the Direct Causticization Reaction Between Sodium Trititanate and Sodium Carbonate", CJChE 78(3): 529-539 (2000).

[13] Palm, M. and Theliander, H., "Kinetic Study on the Direct Causticization reaction Including Titanates and Titanium Dioxide", Chem. Eng. Journ. 68: 87-94 (1997).

[14] Zhuang, Q., Gai, H., van Heiningen, A.R.P., Nohlgren, I. and Theliander, H., "Direct Causticization of Kraft Black Liquor with Recycled Sodium Titanate", 1998 Int. Chem. Recov. Conf, Tampa, Florida, USA, June 1-4, 831-839 (1998). 
[15] Zeng, L., "Kraft Black Liquor Gasification and Direct Causticization in a Fluidized Bed", Ph.D. Thesis, University of New Brunswick, Fredericton, N.B., Canada (1997).

[16] Richards, T., "Recovery of Kraft Black Liquor- Alternative Processes and Systems Analysis", PhD Thesis, Chalmers University, Sweden 2001

[17] Green, R.P., Hough, G., "Chemical Recovery in the Alkaline Pulping Process", $3^{\text {rd }}$ Ed, TAPPI Press, 1992

[19] Sinquefield, S., Sricharoenchaikul, V., Frederick, W.J., Dayton, D., Ratcliff, M., French, R., Carpenter, D., and Lewnard, J., "Black Liquor Gasification I: The Impact of Pressure on C-H-O-S gas Speciation and Tar Components During Pyrolysis", International Chemical Recovery Conference, Whistler BC, June 11-14, 2001

[20] Levenspiel, O., The Chemical Reactor Omnibook, OSU Press

[21] Larson, E., Consoni, S., Katofsky, R., "A Cost-Benefit Assessment of Biomass Gasification Power Generation in the Pulp and Paper Industry", U.S. DOE report, October, 2003.

[22] ChemCad 6.2 process simulation software. www.Chemstations.com

[23] Monson, C.R, Germane, G.J., "A High-Pressure Drop-Tube Facility for Coal Combustion”, Energy and Fuels, 1993, 7, pp928-936. 


\section{APPENDIX A}

\section{Experimental Details}

\section{Pressurized Entrained Flow Reactor (PEFR)}

The experimental portion of the work was performed in a specialized reactor that can mimic the conditions of temperature, pressure, residence time, and gas composition found in full scale gasifiers. A PEFR is a special case of a Laminar Entrained-Flow Reactor. LEFR's have been used extensively to investigate coal, biomass, and black liquor combustion and gasification. The advantages of using a laminar entrained-flow reactor for gasification studies are the rapid heating and cooling rates which allow for experiments at nearly isothermal conditions for controlled amounts of time, and the possibility to make experiments in controlled and well-defined gas atmospheres. In these reactors, solid particles of the material to be gasified are entrained in the primary gas stream and fed into the reactor via a water-cooled injection tube. A secondary gas stream, which constitutes the main part of the reaction gas is preheated to the desired reaction temperature and then enters the reactor concentric to the particles and primary gas stream. The solid particles and the primary gas are rapidly heated (particle heating rates of $10^{4}$ $10^{5}{ }^{\circ} \mathrm{C} / \mathrm{s}$ ) by radiation from the hot reactor walls and convection from the hot secondary gas. The flow pattern through the reactor is laminar to prevent deposition of particles on the reactor walls. The gas and particles exit via a water-cooled probe. They are rapidly cooled by a quench gas that is introduced at the upper tip of the collector. The particles are separated from the sample gas and collected, and the gas is sent to gas analyzers. Placing such a reactor inside a pressure vessel allows for variable pressure. Photos and drawings of the PEFR are shown in Figures A1 - A3.

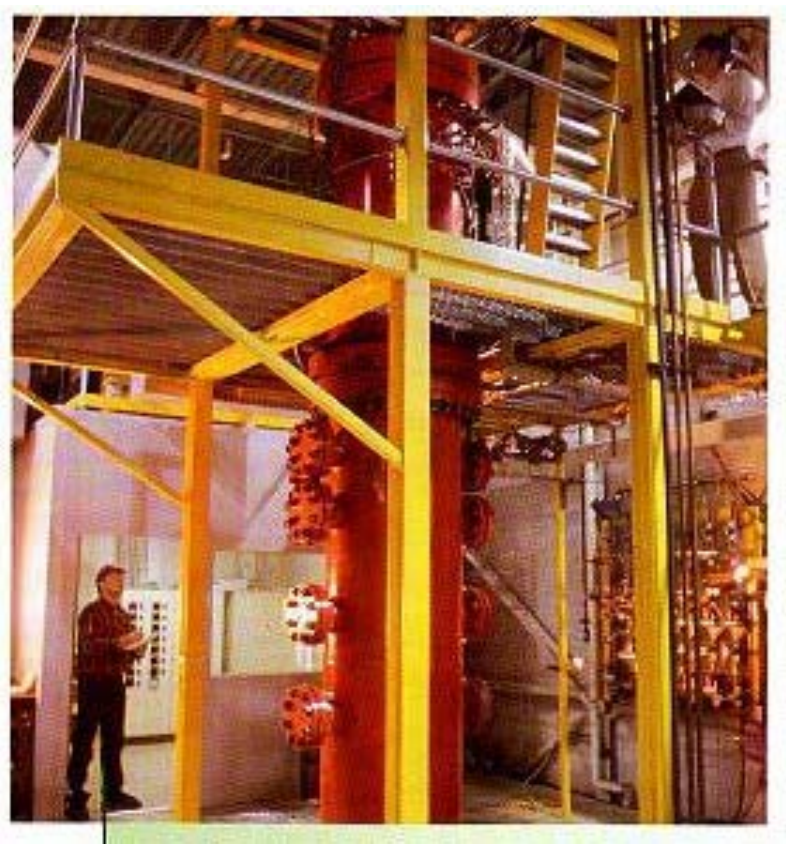

Figure A1. IPST's Pressurized Entrained Flow Reactor 


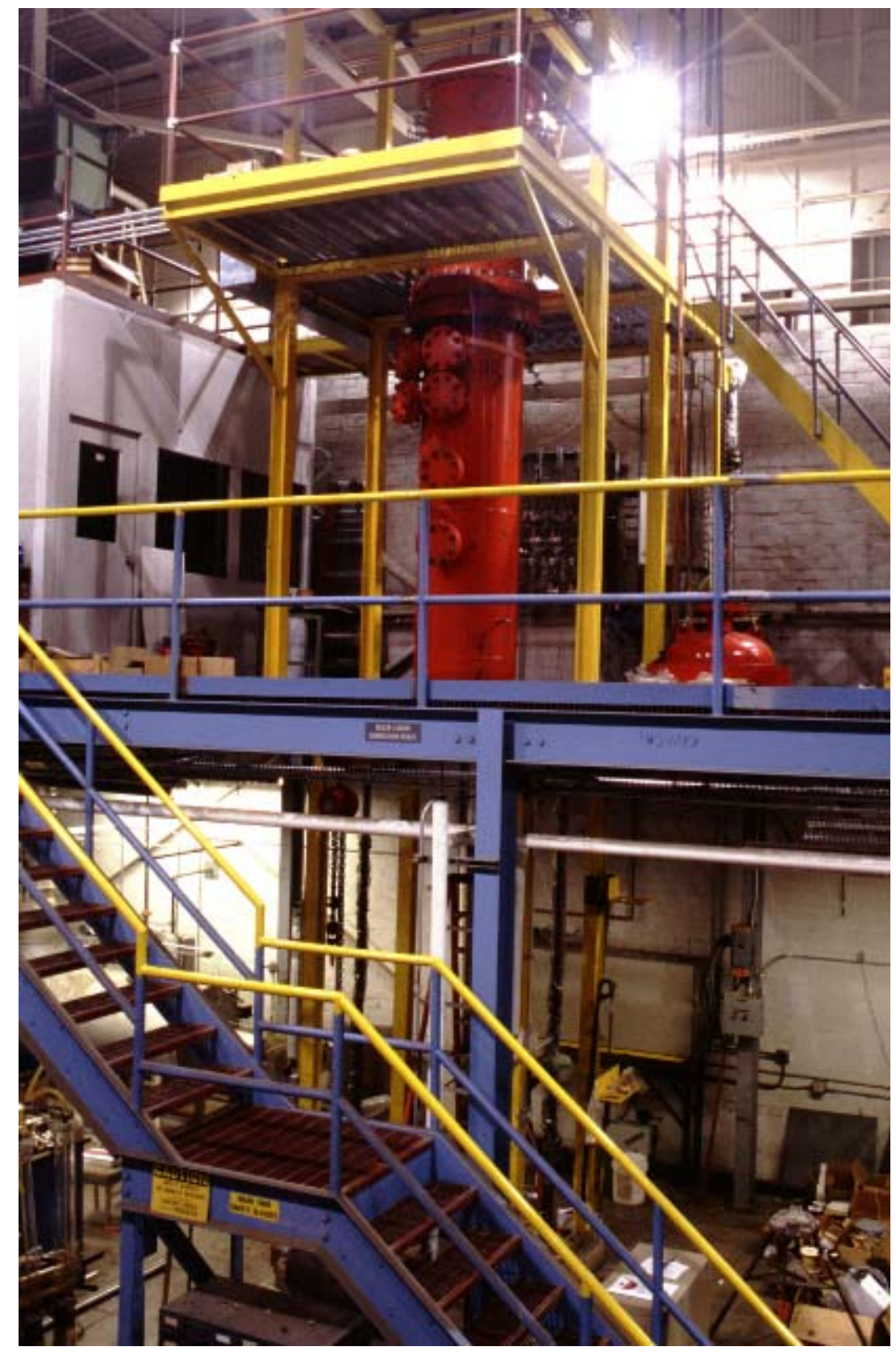

Figure A2. Another view of the PEFR. Ceiling clearance is 39 feet. 


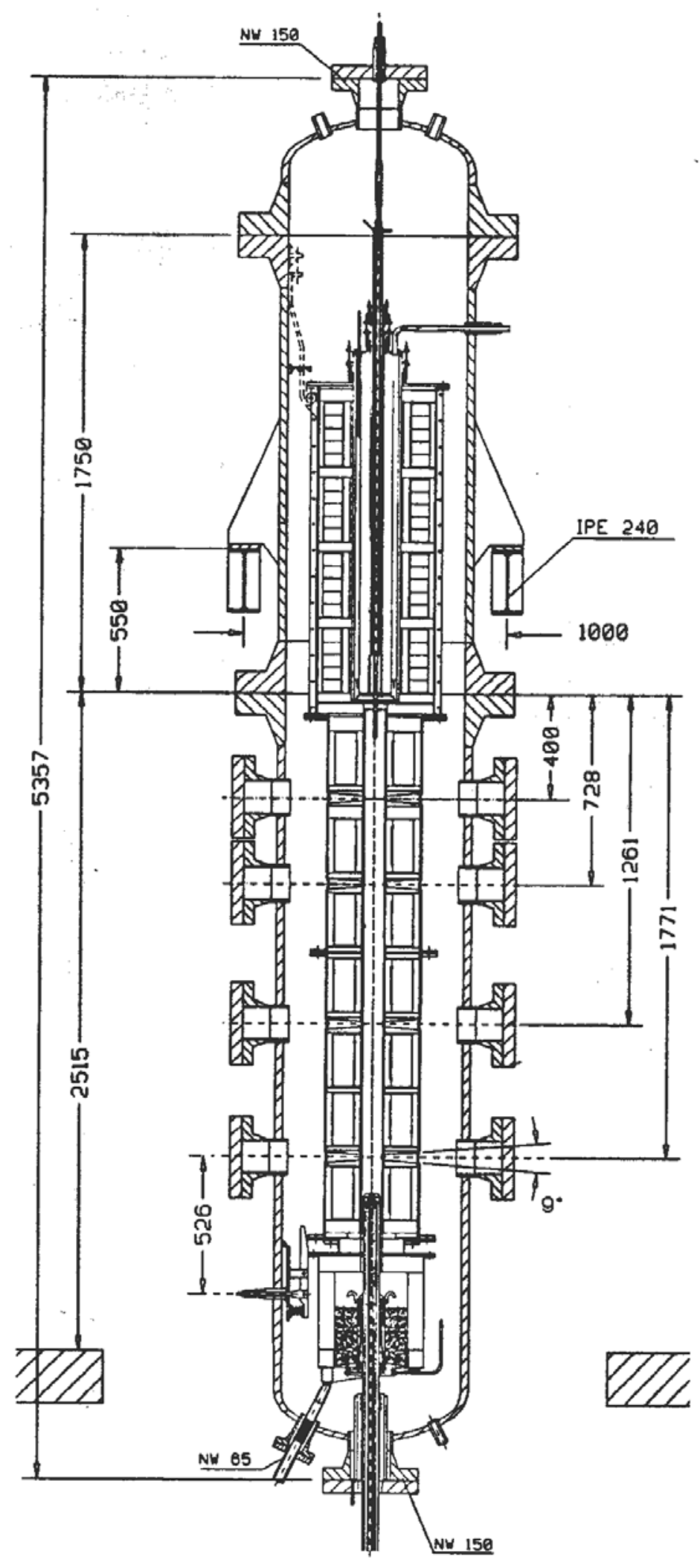

Figure A3. Diagram of the PEFR showing pressure vessel. Dimensions are millimeters. 


\section{Experimental Procedures.}

The mixture ratio (doping levels) reflect the amount calculated from the stoichiometry above to achieve complete causticizing: 68 grams NT3 per 100 grams DBLS. The mixture is prepared wet and then dried in an Anhydro Lab 1 spray drier. The spray-dried solids were then sieved to 63-90 microns for use in the entrained flow reactors.

After reacting the doped liquors in the respective reactors, the residual solid material (char) was collected, and leached (see below). The leachate was then titrated (below) to determine the amount of hydroxide present. This gives the degree of causticizing obtained by reactions 3 and 4 .

\section{Char Leaching and Titration Procedure}

For the titanate and manganate cases, the char must be leached in accordance with reactions (3) and (9) to obtain aqueous hydroxide and the insoluble starting agent (which would be recycled to the gasifier with fresh black liquor in the real world process). The leachate (solution) can then be titrated for determination of carbonate and hydroxide concentrations.

The analytical leaching of the char samples was carried out in a $500 \mathrm{ml}$ 3-necked flask (Figure 4) equipped with a water-cooled condenser, a thermometer and a Pasteur pipette through which $\mathrm{N}_{2}$ gas was bubbling through in order to eliminate air $\left(\mathrm{O}_{2}\right.$ and $\left.\mathrm{CO}_{2}\right)$. While provided constant stirring with magnetic stirrers, the flask was heated via an oil bath in order to bring the water to boil. Evaporated water was condensed on the condenser and fell back down into the flask. When the distilled and deionized water reached its boiling point, $1.000 \mathrm{~g}$ of the recycled sample was added to the boiling water. The leaching time was 90 minutes in order to ensure complete reaction. Some of the samples were leached multiple times as explained in later sections.

After the leaching time had elapsed, the flask with the contents was removed from the oil bath and allowed to cool to room temperature. When cooled, the solution was

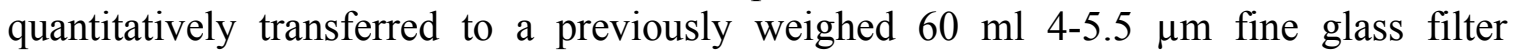
Büchner funnel set up on a 1-liter Erlenmeyer flask and suction filtered by using an aspirator. The filtrate was thereafter transferred to a $250 \mathrm{ml}$ volumetric flask and diluted with distilled and deionized water and put aside for further analysis. The filter cake was dried in an oven overnight $\left(105^{\circ} \mathrm{C}\right)$, and then weighed and stored for further analysis. Finally, the filtrate's caustic concentration was determined by acidimetric titration in a 751 GPD Titrino from Metrohm. 


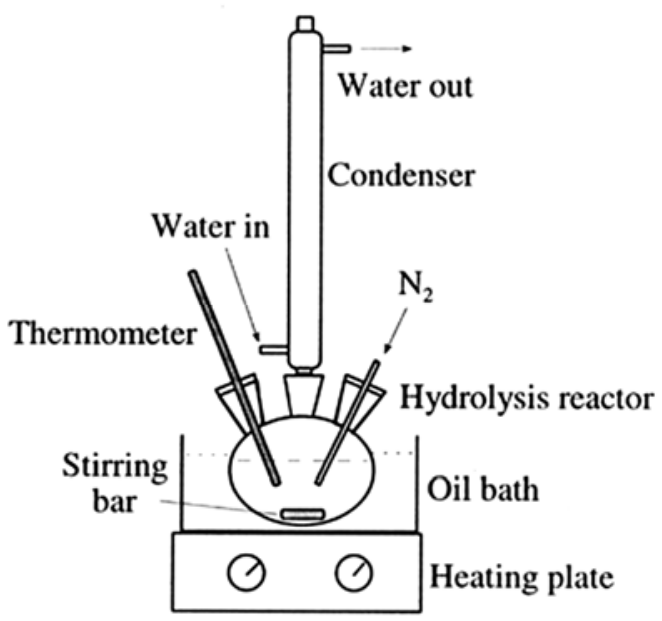

Figure A4. The leaching apparatus.

A $25 \mathrm{ml}$ sample volume of the Na-Ti leachate was pipetted into a beaker. Barium chloride, $10 \mathrm{wt} \%$, was added to the sample to bind any anions, such as carbonate, that would interfere with the titration of $\mathrm{OH}^{-}$. After adding phenolphthalein (PP) indicator, the mixture was titrated to the $\mathrm{PP}$ end point 8.67 with a $0.1 \mathrm{M} \mathrm{HCl}$ solution. The volume of added $\mathrm{HCl}$ was noted and the $\mathrm{NaOH}$ concentration was calculated (see Appendix $\mathrm{B}$ ).

To account for sulfide a formaldehyde solution ( $\mathrm{HCHO}, 40 \%$ in water) was added to convert $\mathrm{Na}_{2} \mathrm{~S}$ to $\mathrm{NaOH}$. If there were any sulfide ions present, the pink color should return. If the pink color of $\mathrm{PP}$ returned, the mixture was titrated again to the $\mathrm{PP}$ end point.

The leaching allows reactions (3) and (4) to release the hydroxide into solution. Previous work [9] has shown that reaction (3) is effectively complete and that reaction (4) proceeds about $65 \%$.

$$
\begin{aligned}
& 3\left(4 \mathrm{Na}_{2} \mathrm{O} \cdot 5 \mathrm{TiO}_{2}\right)(\mathrm{s})+7 \mathrm{H}_{2} \mathrm{O} \leftrightarrow 14 \mathrm{NaOH}(\mathrm{aq})+5\left(\mathrm{Na}_{2} \mathrm{O} \cdot 3 \mathrm{TiO}_{2}\right)(\mathrm{s}) \\
& 2\left(\mathrm{Na}_{2} \mathrm{O} \cdot 3 \mathrm{TiO}_{2}\right)(\mathrm{s})+\mathrm{H}_{2} \mathrm{O} \leftrightarrow 2 \mathrm{NaOH}(\mathrm{aq})+\mathrm{Na}_{2} \mathrm{O} \cdot 6 \mathrm{TiO}_{2}(\mathrm{~s})
\end{aligned}
$$

Since all of the N4T5 is leached back to either NT3 or NT6, the remaining variable is the degree of conversion in reaction (1). Thus the hydroxide recovered is a measure of the carbonate converted in reaction (1). This saves us the extra step of measuring the carbonate content in the char and then leaching the char to measure the hydroxide recovered.

$$
7 \mathrm{Na}_{2} \mathrm{CO}_{3}+5\left(\mathrm{Na}_{2} \mathrm{O} \cdot 3 \mathrm{TiO}_{2}\right)(\mathrm{s}) \leftrightarrow 3\left(4 \mathrm{Na}_{2} \mathrm{O} \cdot 5 \mathrm{TiO}_{2}\right)(\mathrm{s})+7 \mathrm{CO}_{2}(\mathrm{~g})
$$




\section{APPENDIX B}

Experimental Data

The experimental conditions are shown in Table B1 along with resulting char weights. Table B2 shows the data for titration of the char to measure the hydroxide recovered from the leaching. 
Table B1

Experimental Data

\begin{tabular}{|c|c|c|c|c|c|c|c|c|c|c|c|c|c|c|c|c|}
\hline Sample/Date & $\begin{array}{l}\text { Reactor } \\
\text { Temperature } \\
\text { ('C) }\end{array}$ & $\begin{array}{c}\text { Reactor } \\
\text { Pressure } \\
\text { (Bar) }\end{array}$ & $\begin{array}{c}\text { Collector } \\
\text { Height } \\
(\mathrm{mm})\end{array}$ & $\begin{array}{l}\text { Bulk } \\
\text { Velocity } \\
\text { (cm/s) }\end{array}$ & $\begin{array}{c}\text { Initial } \\
\text { Weight (g) }\end{array}$ & $\begin{array}{c}\text { Final } \\
\text { Weight (g) }\end{array}$ & $\begin{array}{l}\text { Fuel Fed } \\
\text { (g) }\end{array}$ & $\underset{\#}{\text { Reynold's }}$ & Gas Composition & $\begin{array}{l}\text { Water } \\
\text { Pump } \\
\text { Setting }\end{array}$ & $\begin{array}{c}\text { Water } \\
\text { Added } \\
\text { (mL/min) }\end{array}$ & 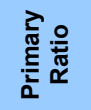 & 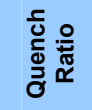 & $\begin{array}{c}\text { Sample } \\
\text { Time } \\
\text { (min.) }\end{array}$ & $\begin{array}{c}\text { Feed Rate } \\
\text { (g/Min) }\end{array}$ & Weight of Char (g) \\
\hline P070329A & 850 & 5 & 1000 & 20 & 699 & 695 & 4 & 851 & $5 \% \mathrm{CO} 2,2 \% \mathrm{H} 2 \mathrm{O}$ & 30 & 1.76 & $3.9: 1$ & $.25: 1$ & 6.5 & 0.6 & 1.5 \\
\hline B & 850 & 5 & 1000 & 20 & 695 & 692 & 3 & 851 & $5 \% \mathrm{CO} 2,2 \% \mathrm{H} 2 \mathrm{O}$ & 30 & 1.76 & $3.9: 1$ & $.25: 1$ & 10 & 0.3 & 2.36 \\
\hline P070403A & 850 & 5 & 1000 & 20 & 795 & 787 & 8 & 851 & $5 \% \mathrm{CO} 2,2 \% \mathrm{H} 2 \mathrm{O}$ & 30 & 1.76 & $3.9: 1$ & $.25: 1$ & 10 & 0.8 & 5.93 \\
\hline B & 850 & 5 & 1000 & 20 & 787 & 782 & 5 & 851 & $5 \% \mathrm{CO} 2,2 \% \mathrm{H} 2 \mathrm{O}$ & 30 & 1.76 & $3.9: 1$ & $.25: 1$ & 10 & 0.5 & 3.94 \\
\hline P070411A & 850 & 5 & 500 & 20 & 733 & 728 & 5 & 851 & $5 \% \mathrm{CO} 2,2 \% \mathrm{H} 2 \mathrm{O}$ & 30 & 1.76 & $3.9: 1$ & $.25: 1$ & 10 & 0.5 & 3.03 \\
\hline B & 850 & 5 & 500 & 20 & 728 & 726 & 2 & 851 & $5 \% \mathrm{CO} 2,2 \% \mathrm{H} 2 \mathrm{O}$ & 30 & 1.76 & $3.9: 1$ & $.25: 1$ & 10 & 0.2 & 1.78 \\
\hline P070412A & 850 & 5 & 500 & 20 & 720 & 718 & 2 & 875 & $10 \% \mathrm{CO} 2,2 \% \mathrm{H} 2 \mathrm{O}$ & 30 & 1.76 & 3.9:1 & $.25: 1$ & 10 & 0.2 & 1.33 \\
\hline B & 850 & 5 & 500 & 20 & 718 & 716 & 2 & 875 & $10 \% \mathrm{CO} 2,2 \% \mathrm{H} 2 \mathrm{O}$ & 30 & 1.76 & $3.9: 1$ & $.25: 1$ & 10 & 0.2 & 1.58 \\
\hline P070426A & 850 & 5 & 1998 & 20 & 722 & 718 & 4 & 828 & $2 \% \mathrm{H} 2 \mathrm{O}$ & 30 & 1.76 & $3.9: 1$ & $.25: 1$ & 10 & 0.4 & 0.94 \\
\hline B & 850 & 5 & 1998 & 20 & 718 & 715 & 3 & 828 & $2 \% \mathrm{H} 2 \mathrm{O}$ & 30 & 1.76 & $3.9: 1$ & $.25: 1$ & 10 & 0.3 & 0.35 \\
\hline P070427A & 850 & 5 & 1996 & 20 & 729 & 723 & 6 & 832 & $1 \% \mathrm{CO} 2,2 \% \mathrm{H} 2 \mathrm{O}$ & 30 & 1.76 & 3.9:1 & $.25: 1$ & 15 & 0.4 & 0.74 \\
\hline B & 850 & 5 & 1996 & 20 & 723 & 714 & 9 & 832 & $1 \% \mathrm{CO} 2,2 \% \mathrm{H} 2 \mathrm{O}$ & 30 & 1.76 & $3.9: 1$ & $.25: 1$ & 18 & 0.5 & 1.07 \\
\hline P070502A & 850 & 5 & 1998 & 20 & 708 & 703 & 5 & 837 & $2 \% \mathrm{CO} 2,2 \% \mathrm{H} 2 \mathrm{O}$ & 30 & 1.76 & $3.9: 1$ & $.25: 1$ & 15 & 0.333333 & 0.65 \\
\hline B & 850 & 5 & 1998 & 20 & 703 & 698 & 5 & 837 & $2 \% \mathrm{CO} 2,2 \% \mathrm{H} 2 \mathrm{O}$ & 30 & 1.76 & $3.9: 1$ & $.25: 1$ & 20 & 0.25 & 0.11 \\
\hline $\mathrm{C}$ & 850 & 5 & 1998 & 20 & 698 & 695 & 3 & 851 & $5 \% \mathrm{CO} 2,2 \% \mathrm{H} 2 \mathrm{O}$ & 30 & 1.76 & $3.9: 1$ & $.25: 1$ & 20 & 0.15 & 1.45 \\
\hline $\mathrm{D}$ & 850 & 5 & 1998 & 20 & 695 & 695 & 0 & 851 & $5 \% \mathrm{CO} 2,2 \% \mathrm{H} 2 \mathrm{O}$ & 30 & 1.76 & 3.9:1 & $.25: 1$ & 8 & 0 & 0 \\
\hline P070503A & 850 & 5 & 1998 & 20 & 590 & 560 & 30 & 875 & $10 \% \mathrm{CO} 2,2 \% \mathrm{H} 2 \mathrm{O}$ & 30 & 1.76 & $3.9: 1$ & $.25: 1$ & 2 & 15 & 2.4 \\
\hline B & 850 & 5 & 1998 & 20 & 528 & 585 & -57 & 875 & $10 \% \mathrm{CO} 2,2 \% \mathrm{H} 2 \mathrm{O}$ & 30 & 1.76 & $3.9: 1$ & $.25: 1$ & 4.5 & -12.6667 & 1.77 \\
\hline $\mathrm{C}$ & 850 & 5 & 1998 & 20 & 546 & 580 & -34 & 851 & $5 \% \mathrm{CO} 2,2 \% \mathrm{H} 2 \mathrm{O}$ & 30 & 1.76 & $3.9: 1$ & $.25: 1$ & 6 & -5.66667 & 0.68 \\
\hline D & 850 & 5 & 1998 & 20 & 660 & 643 & 17 & 837 & $2 \% \mathrm{CO} 2,2 \% \mathrm{H} 2 \mathrm{O}$ & 30 & 1.76 & 3.9:1 & $.25: 1$ & 2.75 & 6.181818 & 5.43 \\
\hline $\mathrm{E}$ & 850 & 5 & 1998 & 20 & 628 & 644 & -16 & 828 & $2 \% \mathrm{H} 2 \mathrm{O}$ & 30 & 1.76 & $3.9: 1$ & $.25: 1$ & 5 & -3.2 & 4.91 \\
\hline P070507A & 950 & 5 & 1998 & 20 & 706 & 696 & 10 & 832 & $1 \% \mathrm{CO} 2,2 \% \mathrm{H} 2 \mathrm{O}$ & 30 & 1.76 & 3.9:1 & $.25: 1$ & 4 & 2.5 & no char \\
\hline B & 950 & 5 & 1998 & 20 & 695 & 687 & 8 & 837 & $2 \% \mathrm{CO} 2,2 \% \mathrm{H} 2 \mathrm{O}$ & 30 & 1.76 & $3.9: 1$ & $.25: 1$ & 4 & 2 & no char \\
\hline $\mathrm{C}$ & 950 & 5 & 1998 & 20 & 687 & 676 & 11 & 851 & $5 \% \mathrm{CO} 2,2 \% \mathrm{H} 2 \mathrm{O}$ & 30 & 1.76 & $3.9: 1$ & $.25: 1$ & 10 & 1.1 & no char \\
\hline $\begin{array}{l}\text { P070509A } \\
\end{array}$ & 950 & 5 & 1998 & 20 & 667 & 661 & 6 & 480 & $1 \% \mathrm{CO} 2,2 \% \mathrm{H} 2 \mathrm{O}$ & 30 & 1.76 & $3.9: 1$ & $.25: 1$ & 4 & 1.5 & 0.15 \\
\hline B & 950 & 5 & 1998 & 20 & 661 & 655 & 6 & 483 & $2 \% \mathrm{CO} 2,2 \% \mathrm{H} 2 \mathrm{O}$ & 30 & 1.76 & 3.9:1 & $.25: 1$ & 4 & 1.5 & 0.7 \\
\hline P070510A & 950 & 5 & 1998 & 20 & 654 & 650 & 4 & 480 & $1 \% \mathrm{CO} 2,2 \% \mathrm{H} 2 \mathrm{O}$ & 30 & 1.76 & $3.9: 1$ & $.25: 1$ & 7 & 0.571429 & \\
\hline P070605A & 950 & 5 & 1999 & 20 & 755 & 751 & 4 & 477 & $2 \% \mathrm{H} 2 \mathrm{O}$ & 14.1 & 1.04 & $3.9: 1$ & $.25: 1$ & 10 & 0.4 & 0 \\
\hline $\mathrm{B}$ & 950 & 5 & 1999 & 20 & 751 & 748 & 3 & 480 & $1 \% \mathrm{CO} 2,2 \% \mathrm{H} 2 \mathrm{O}$ & 14.1 & 1.04 & 3.9:1 & $.25: 1$ & 10 & 0.3 & 0 \\
\hline P070801A & 950 & 5 & 1999 & 10 & 724 & 717 & 7 & 241 & $2 \% \mathrm{CO} 2,2 \% \mathrm{H} 2 \mathrm{O}$ & 3 & 0.52 & $39 \cdot 1$ & $25: 1$ & 10 & 07 & not enough char to collect \\
\hline $\mathrm{B}$ & 950 & 5 & 1999 & 10 & 717 & 712 & 5 & 241 & $2 \% \mathrm{CO} 2,2 \% \mathrm{H} 2 \mathrm{O}$ & 3 & 0.52 & $3.9: 1$ & $.25: 1$ & 10 & 0.5 & not enough char to collect \\
\hline P070803A & 950 & 5 & 1999 & 10 & 739 & 731 & 8 & 241 & $2 \% \mathrm{CO} 2,2 \% \mathrm{H} 2 \mathrm{O}$ & 3.5 & 0.55 & $1.5: 1$ & $1 .: 1$ & 10 & 0.8 & not enough char to collect \\
\hline $\mathrm{B}$ & 950 & 5 & 1999 & 10 & 731 & 725 & 6 & 241 & $2 \% \mathrm{CO} 2,2 \% \mathrm{H} 2 \mathrm{O}$ & 3.5 & 0.55 & $1.5: 1$ & $1 .: 1$ & 10 & 0.6 & not enough char to collect \\
\hline P070821A & 950 & 5 & 1999 & 10 & 733 & 727 & 6 & 241 & $2 \% \mathrm{CO} 2,2 \% \mathrm{H} 2 \mathrm{O}$ & 3.5 & 0.55 & $1.5: 1$ & $1 .: 1$ & 10 & 0.6 & plug - not enough char to collect \\
\hline $\mathrm{B}$ & 950 & 5 & 1999 & 10 & 727 & 722 & 5 & 241 & $2 \% \mathrm{CO} 2,2 \% \mathrm{H} 2 \mathrm{O}$ & 3.5 & 0.55 & 1.5:1 & $1 .: 1$ & 10 & 0.5 & plug - not enough char to collect \\
\hline P070823A & 950 & 5 & 1999 & 10 & 732 & 725 & 7 & 241 & $2 \% \mathrm{CO} 2,2 \% \mathrm{H} 2 \mathrm{O}$ & 3.5 & 0.55 & 1.5:1 & $1 .: 1$ & 10 & 0.7 & $\begin{array}{ll}1.14 \\
\end{array}$ \\
\hline
\end{tabular}


Table B1 (continued)

\begin{tabular}{|c|c|c|c|c|c|c|c|c|c|c|c|c|c|c|c|c|c|}
\hline Sample/Date & $\begin{array}{c}\text { Reactor } \\
\text { Temperature } \\
\text { ('C) }\end{array}$ & $\begin{array}{l}\text { Reactor } \\
\text { Pressure } \\
\text { (Bar) }\end{array}$ & $\begin{array}{c}\text { Collector } \\
\text { Hieight } \\
\text { (mm) }\end{array}$ & $\begin{array}{l}\text { Bulk } \\
\text { Velocity } \\
\text { (cm/s) }\end{array}$ & $\begin{array}{c}\text { Initial } \\
\text { Weight (g) }\end{array}$ & $\begin{array}{c}\text { Final } \\
\text { Weight (g) }\end{array}$ & $\begin{array}{l}\text { Fuel Fed } \\
\text { (g) }\end{array}$ & $\underset{\#}{\text { Reynold's }}$ & Gas Composition & $\begin{array}{l}\text { Water } \\
\text { Pump } \\
\text { Setting }\end{array}$ & $\begin{array}{c}\text { Water } \\
\text { Added } \\
\text { (mL/min) }\end{array}$ & 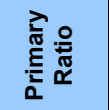 & 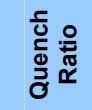 & $\begin{array}{c}\text { Sample } \\
\text { Timee } \\
\text { (min.) }\end{array}$ & $\begin{array}{c}\text { Feed Rate } \\
\text { (g/Min) }\end{array}$ & Weight of Char (g) & \\
\hline $\mathrm{B}$ & 950 & 5 & 1999 & 10 & 725 & 718 & 7 & 241 & $2 \% \mathrm{CO} 2,2 \% \mathrm{H} 2 \mathrm{O}$ & 3.5 & 0.55 & $1.5: 1$ & $1 .: 1$ & 12 & 0.58 & & 0.55 \\
\hline $\mathrm{C}$ & 950 & 5 & 1999 & 10 & 718 & 710 & 8 & 245 & $5 \% \mathrm{CO} 2,2 \% \mathrm{H} 2 \mathrm{O}$ & 3.5 & 0.55 & $1.5: 1$ & $1 .: 1$ & 20 & 0.4 & & 1.45 \\
\hline $\mathrm{D}$ & 950 & 5 & 1999 & 10 & 710 & 702 & 8 & 245 & $5 \% \mathrm{CO} 2,2 \% \mathrm{H} 2 \mathrm{O}$ & 3.5 & 0.55 & $1.5: 1$ & $1 .: 1$ & 22 & 0.363636 & & 1.44 \\
\hline $\begin{array}{l}\text { P070831A } \\
\end{array}$ & 850 & 5 & 1999 & 10 & 730 & $\mathrm{xxx}$ & & 279 & $2 \% \mathrm{CO} 2,2 \% \mathrm{H} 2 \mathrm{O}$ & 4.3 & 0.60 & $1.5: 1$ & $1 .: 1$ & 20 & & & 3.93 \\
\hline $\mathrm{B}$ & 850 & 5 & 1999 & 10 & $\mathrm{xxx}$ & $\mathrm{xxx}$ & & 279 & $2 \% \mathrm{CO} 2,2 \% \mathrm{H} 2 \mathrm{O}$ & 4.3 & 0.60 & $1.5: 1$ & $1 .: 1$ & 20 & & & 2.86 \\
\hline $\mathrm{C}$ & 850 & 5 & 1999 & 10 & $\mathrm{xxx}$ & $\mathrm{xxx}$ & & 284 & $5 \% \mathrm{CO} 2,2 \% \mathrm{H} 2 \mathrm{O}$ & 4.3 & 0.60 & $1.5: 1$ & $1 .: 1$ & 25 & & & 1.76 \\
\hline $\bar{D}$ & 850 & 5 & 1999 & 10 & $\mathrm{xxx}$ & $\mathrm{xxx}$ & & 284 & $5 \% \mathrm{CO} 2,2 \% \mathrm{H} 2 \mathrm{O}$ & 4.3 & 0.60 & $1.5: 1$ & $1 .: 1$ & 25 & & & 1.52 \\
\hline P070905A & 850 & 5 & 1999 & 10 & 726 & 716 & 10 & 277 & $1 \% \mathrm{CO} 2,2 \% \mathrm{H} 2 \mathrm{O}$ & 4.3 & 0.60 & $1.5: 1$ & $1 .: 1$ & 20 & 0.5 & & 1.19 \\
\hline B & 850 & 5 & 1999 & 10 & 716 & 708 & 8 & 277 & $1 \% \mathrm{CO} 2,2 \% \mathrm{H} 2 \mathrm{O}$ & 4.3 & 0.60 & $1.5: 1$ & $1 .: 1$ & 20 & 0.4 & & 1.56 \\
\hline $\mathrm{C}$ & 950 & 5 & 1999 & 10 & 708 & 697 & 11 & 240 & $1 \% \mathrm{CO} 2,2 \% \mathrm{H} 2 \mathrm{O}$ & 3.5 & 0.55 & $1.5: 1$ & $1 .: 1$ & 25 & 0.44 & & 1.19 \\
\hline $\mathrm{D}$ & 950 & 5 & 1999 & 10 & 697 & 690 & 7 & 240 & $1 \% \mathrm{CO} 2,2 \% \mathrm{H} 2 \mathrm{O}$ & 3.5 & 0.55 & $1.5: 1$ & $1 .: 1$ & 25 & 0.28 & & 0.84 \\
\hline P080318A & 850 & 5 & 1900 & 10 & 713 & 710 & 3 & 292 & $10 \% \mathrm{CO} 2,2 \% \mathrm{H} 2 \mathrm{O}$ & 4.5 & 0.61 & $1.25: 1$ & $1: 33$ & 10 & 0.3 & 1.2919 & \\
\hline P080318B & 850 & 5 & 1900 & 10 & 710 & 707 & 3 & 292 & $10 \% \mathrm{CO} 2,2 \% \mathrm{H} 2 \mathrm{O}$ & 4.5 & 0.61 & $1.25: 1$ & $1: 33$ & 10 & 0.3 & 0.9533 & \\
\hline P080318C & 850 & 5 & 1900 & 10 & 707 & 702 & 5 & 308 & $20 \% \mathrm{CO} 2,2 \% \mathrm{H} 2 \mathrm{O}$ & 4.5 & 0.61 & $1.25: 1$ & $1: 33$ & 20 & 0.25 & 1.6968 & \\
\hline P080318D & 850 & 5 & 1900 & 10 & 702 & 698 & 4 & 308 & $20 \% \mathrm{CO} 2,2 \% \mathrm{H} 2 \mathrm{O}$ & 4.5 & 0.61 & $1.25: 1$ & $1: 33$ & 20 & 0.2 & 1.4705 & \\
\hline P080320A & 850 & 5 & 1900 & 10 & 689 & 683 & 6 & 316 & $40 \% \mathrm{CO} 2,2 \% \mathrm{H} 2 \mathrm{O}$ & 4.5 & 0.61 & $1.25: 1$ & $1: 33$ & 25 & 0.24 & & \\
\hline P080320B & 850 & 5 & 1900 & 10 & 683 & 679 & 4 & 316 & $40 \% \mathrm{CO} 2,2 \% \mathrm{H} 2 \mathrm{O}$ & 4.5 & 0.61 & $1.25: 1$ & $1: 33$ & 25 & 0.16 & & \\
\hline P080424A & 850 & 5 & 1990 & 10 & 698 & 694 & 4 & 288 & $7.5 \% \mathrm{CO} 2,2 \% \mathrm{H} 2 \mathrm{O}$ & 4.5 & 0.61 & $1.25: 1$ & $1: 33$ & 15 & 0.27 & 1.21 & \\
\hline P080424B & 850 & 5 & 1900 & 10 & 694 & 690 & 4 & 288 & $7.5 \% \mathrm{CO} 2,2 \% \mathrm{H} 2 \mathrm{O}$ & 4.5 & 0.61 & $1.25: 1$ & $1: 33$ & 15 & 0.27 & 1.21 & \\
\hline P080424C & 850 & 5 & 1900 & 10 & 690 & 685 & 5 & 292 & $10 \% \mathrm{CO} 2,2 \% \mathrm{H} 2 \mathrm{O}$ & 4.5 & 0.61 & $1.25: 1$ & $1: 33$ & 20 & 0.25 & 1.41 & \\
\hline P080424D & 850 & 5 & 1900 & 10 & 685 & 680 & 5 & 292 & $10 \% \mathrm{CO} 2,2 \% \mathrm{H} 2 \mathrm{O}$ & 4.5 & 0.61 & $1.25: 1$ & $1: 33$ & 20 & 0.25 & 1.23 & \\
\hline P080508A & 850 & 5 & 1900 & 10 & 684 & 682 & 2 & 292 & $10 \% \mathrm{CO} 2,2 \% \mathrm{H} 2 \mathrm{O}$ & 4.5 & 0.61 & $1.25: 1$ & $1: 33$ & 18 & 0.11 & ---- & \\
\hline P050830A & 850 & 5 & 1900 & 10 & 684 & 681 & 3 & 300 & $15 \% \mathrm{CO} 2,2 \% \mathrm{H} 2 \mathrm{O}$ & 4.1 & 0.59 & $1.25: 1$ & $1: 33$ & 20 & 0.15 & 1.04 & \\
\hline P050830B & 850 & 5 & 1900 & 10 & 681 & 678 & 3 & 300 & $15 \% \mathrm{CO} 2,2 \% \mathrm{H} 2 \mathrm{O}$ & 4.1 & 0.59 & $1.25: 1$ & $1: 33$ & 20 & 0.15 & 1.05 & \\
\hline P080530C & 850 & 5 & 1900 & 10 & 678 & 674 & 4 & 308 & $20 \% \mathrm{CO} 2,2 \% \mathrm{H} 2 \mathrm{O}$ & 4.5 & 0.61 & $1.25: 1$ & $1: 33$ & 20 & 0.20 & & \\
\hline P080530D & 850 & 5 & 1900 & 10 & 674 & 671 & 3 & 308 & $20 \% \mathrm{CO} 2,2 \% \mathrm{H} 2 \mathrm{O}$ & 4.5 & 0.61 & $1.25: 1$ & $1: 33$ & 20 & 0.15 & & \\
\hline P080626A & 850 & 5 & 1900 & 10 & 714 & 710 & 4 & 292 & $10 \% \mathrm{CO} 2,2 \% \mathrm{H} 2 \mathrm{O}$ & 4.5 & 0.61 & $1.25: 1$ & $1: 33$ & 20 & 0.20 & 1.31 & \\
\hline P080626B & 850 & 5 & 1900 & 10 & 710 & 704 & 6 & 292 & $10 \% \mathrm{CO} 2,2 \% \mathrm{H} 2 \mathrm{O}$ & 4.5 & 0.61 & $1.25: 1$ & $1: 33$ & 20 & 0.30 & 1.27 & \\
\hline
\end{tabular}


Table B2

Leaching Data

\begin{tabular}{|c|c|c|c|c|c|c|c|c|c|c|c|c|c|c|c|}
\hline Sample & Temp & Pressure & $\% \mathrm{CO} 2$ & $\mathrm{P}$ & Leaching Time & Sample Wt. & Empty Funnel & Funnel+Residue & Residue & Leachate & aliquot & {$[\mathrm{HCl}]$ titrant } & Vol. $\mathrm{HCl}$ & {$[\mathrm{NaOH}]$} & {$[\mathrm{NaOH}]$} \\
\hline ID & $\mathrm{C}$ & bar & & $\mathrm{CO} 2$, bar & (min) & (g) & (g) & (g) & (g) & vol. $(\mathrm{mL})$ & $(\mathrm{mL})$ & conc & $(\mathrm{mL})$ & $(\mathrm{mol} / \mathrm{L})$ & (mol/g char) \\
\hline P070403A & 850 & 5 & $5.00 \%$ & 0.25 & 90 & 1.0001 & 61.1536 & 61.5930 & 0.4394 & 250 & 25 & 0.1 & 0 & $0.00 \mathrm{E}+00$ & $0.00 \mathrm{E}+00$ \\
\hline P070403B & 850 & 5 & $5.00 \%$ & 0.25 & 90 & 0.9999 & 61.5247 & 61.9543 & 0.4296 & 250 & 25 & 0.1 & 0 & $0.00 \mathrm{E}+00$ & $0.00 \mathrm{E}+00$ \\
\hline P070411A & 850 & 5 & $5.00 \%$ & 0.25 & 90 & 0.9994 & 60.9279 & 61.3975 & 0.4696 & 250 & 25 & 0.1 & 0 & $0.00 \mathrm{E}+00$ & $0.00 \mathrm{E}+00$ \\
\hline P070411B & 850 & 5 & $5.00 \%$ & 0.25 & 90 & 0.9996 & 61.1155 & 61.5222 & 0.4067 & 250 & 25 & 0.1 & 0 & $0.00 \mathrm{E}+00$ & $0.00 \mathrm{E}+00$ \\
\hline & & & & & & & & & & & & & & & \\
\hline P070412A & 850 & 5 & $10.00 \%$ & 0.5 & 90 & 0.9988 & 70.6045 & 70.9971 & 0.3926 & 250 & 25 & 0.1 & 0 & $0.00 \mathrm{E}+00$ & $0.00 \mathrm{E}+00$ \\
\hline P070412B & 850 & 5 & $10.00 \%$ & 0.5 & 90 & 0.9985 & 61.4982 & 61.7307 & 0.2325 & 250 & 25 & 0.1 & 0 & $0.00 \mathrm{E}+00$ & $0.00 \mathrm{E}+00$ \\
\hline & & & & & & & & & & & & & & & \\
\hline P070426A & 850 & 5 & $0.00 \%$ & 0 & 90 & 0.6196 & 60.9201 & 61.1725 & 0.2524 & 250 & 25 & 0.1 & 0.214 & $8.56 \mathrm{E}-04$ & $3.45 \mathrm{E}-04$ \\
\hline P070427B & 850 & 5 & $1.00 \%$ & 0.05 & 90 & 0.8187 & 61.0935 & 61.4232 & 0.3297 & 250 & 25 & 0.1 & 0 & $0.00 \mathrm{E}+00$ & $0.00 \mathrm{E}+00$ \\
\hline $\mathrm{P} 070502 \mathrm{~A}$ & 850 & 5 & $2.00 \%$ & 0.1 & 90 & 0.4830 & 61.0511 & 61.2008 & 0.1497 & 250 & 25 & 0.1 & 0.136 & $5.44 \mathrm{E}-04$ & $2.82 \mathrm{E}-04$ \\
\hline P070502C & 850 & 5 & $2.00 \%$ & 0.1 & 90 & 0.9990 & 60.9202 & 61.3140 & 0.3938 & 250 & 25 & 0.1 & 0 & $0.00 \mathrm{E}+00$ & $0.00 \mathrm{E}+00$ \\
\hline P070503A & 850 & 5 & $5.00 \%$ & 0.25 & 90 & 0.9997 & 61.4636 & 61.8523 & 0.3887 & 250 & 25 & 0.1 & 0 & $0.00 \mathrm{E}+00$ & $0.00 \mathrm{E}+00$ \\
\hline P070503B & 850 & 5 & $5.00 \%$ & 0.25 & 90 & 0.9996 & 70.6021 & 71.0118 & 0.4097 & 250 & 25 & 0.1 & 0 & $0.00 \mathrm{E}+00$ & $0.00 \mathrm{E}+00$ \\
\hline P070503C & 850 & 5 & $5.00 \%$ & 0.25 & 90 & 0.4956 & 61.0622 & 61.2453 & 0.1831 & 250 & 25 & 0.1 & 0 & $0.00 \mathrm{E}+00$ & $0.00 \mathrm{E}+00$ \\
\hline P070503D & 850 & 5 & $2.00 \%$ & 0.1 & 90 & 0.9994 & 60.5069 & 61.0163 & 0.5094 & 250 & 25 & 0.1 & 0.296 & $1.18 \mathrm{E}-03$ & $2.96 \mathrm{E}-04$ \\
\hline P070503D & 850 & 5 & $2.00 \%$ & 0.1 & 90 & 0.9994 & 60.5069 & 61.0163 & 0.5094 & 250 & 25 & 0.1 & 0.276 & $1.10 \mathrm{E}-03$ & $2.76 \mathrm{E}-04$ \\
\hline $\begin{array}{l}\text { P070503E } \\
\end{array}$ & 850 & 5 & $2.00 \%$ & 0.1 & 90 & 1.0002 & 69.4719 & 69.9576 & 0.4857 & 250 & 25 & 0.1 & 0.330 & $1.32 \mathrm{E}-03$ & $3.30 \mathrm{E}-04$ \\
\hline SB070607 & 850 & 5 & $0.00 \%$ & 0 & 90 & 1.002 & 70.6033 & 71.3805 & 0.7772 & 250 & 25 & 0.1 & 3.942 & $1.58 \mathrm{E}-02$ & $3.93 \mathrm{E}-03$ \\
\hline SB070607 & 850 & 5 & $0.00 \%$ & 0 & 90 & 1.002 & 70.6033 & 71.3805 & 0.7772 & 250 & 25 & 0.1 & 3.954 & $1.58 \mathrm{E}-02$ & $3.95 \mathrm{E}-03$ \\
\hline P070828A & 850 & 5 & $2.00 \%$ & 0.1 & 90 & 0.7668 & 60.5076 & 610199 & 05123 & 250 & 25 & 01 & 1672 & $669 \mathrm{E}-03$ & $218 \mathrm{E}-03$ \\
\hline P070828C & 850 & 5 & $5.00 \%$ & 0.25 & 90 & 0.9761 & 61.0582 & 61.7246 & 0.6664 & 250 & 25 & 0.1 & 2.258 & $9.03 \mathrm{E}-03$ & $2.31 \mathrm{E}-03$ \\
\hline P070828D & 850 & 5 & $5.00 \%$ & 0.25 & 90 & 0.9407 & 76.1224 & 76.6906 & 0.5682 & 250 & 25 & 0.1 & 1.512 & $6.05 \mathrm{E}-03$ & $1.61 \mathrm{E}-03$ \\
\hline P070831A & 850 & 5 & $2.00 \%$ & 0.1 & 90 & 0.9974 & 61.4544 & 62.1815 & 0.7271 & 250 & 25 & 0.1 & 2.826 & $1.13 \mathrm{E}-02$ & $2.83 \mathrm{E}-03$ \\
\hline $\begin{array}{l}\text { P070831B } \\
\end{array}$ & 850 & 5 & $2.00 \%$ & 0.1 & 90 & 0.9907 & 61.0377 & 61.7522 & 0.7145 & 250 & 25 & 0.1 & 2.584 & $1.03 \mathrm{E}-02$ & $2.61 \mathrm{E}-03$ \\
\hline P070831C & 850 & 5 & $5.00 \%$ & 0.25 & 90 & 0.9993 & 60.5133 & 61.2406 & 0.7273 & 250 & 25 & 0.1 & 2.894 & 1.16E-02 & $2.90 \mathrm{E}-03$ \\
\hline P070831D & 850 & 5 & $5.00 \%$ & 0.25 & 90 & 0.9859 & 61.0568 & 61.7739 & 0.7171 & 250 & 25 & 0.1 & 2.700 & $1.08 \mathrm{E}-02$ & $2.74 \mathrm{E}-03$ \\
\hline & & & & & & & & & & & & & & & \\
\hline P070905A & 850 & 5 & $1.00 \%$ & 0.05 & 90 & 0.9633 & 76.1255 & 76.8231 & 0.6976 & 250 & 25 & 0.1 & 2.566 & $1.03 \mathrm{E}-02$ & $2.66 \mathrm{E}-03$ \\
\hline P070905B & 850 & 5 & $1.00 \%$ & 0.05 & 90 & 0.9979 & 61.4583 & 62.2140 & 0.7557 & 250 & 25 & 0.1 & 3.024 & $1.21 \mathrm{E}-02$ & $3.03 \mathrm{E}-03$ \\
\hline P070905C & 850 & 5 & $1.00 \%$ & 0.05 & 90 & 0.7949 & 61.0321 & 61.5965 & 0.5644 & 250 & 25 & 0.1 & 2.214 & $8.86 \mathrm{E}-03$ & 2.79E-03 \\
\hline
\end{tabular}


Table B2 (continued)

\begin{tabular}{|c|c|c|c|c|c|c|c|c|c|c|c|c|c|c|c|}
\hline Sample & Temp & Pressure & $\% \mathrm{CO} 2$ & $\mathrm{P}$ & Leaching Time & $\begin{array}{c}\text { Sample } \\
\text { Wt. }\end{array}$ & Empty Funnel & Funnel+Residue & Residue & Leachate & aliquot & {$[\mathrm{HCl}]$ titrant } & Vol. $\mathrm{HCl}$ & {$[\mathrm{NaOH}]$} & {$[\mathrm{NaOH}]$} \\
\hline ID & $\mathrm{C}$ & bar & & $\mathrm{CO} 2$, bar & (min) & (g) & (g) & (g) & (g) & vol. $(\mathrm{mL})$ & $(\mathrm{mL})$ & conc & $(\mathrm{mL})$ & $(\mathrm{mol} / \mathrm{L})$ & (mol/g char) \\
\hline P070905D & 850 & 5 & $1.00 \%$ & 0.05 & 90 & 0.5529 & 61.0593 & 61.4379 & 0.3786 & 250 & 25 & 0.1 & 1.244 & $4.98 \mathrm{E}-03$ & $2.25 \mathrm{E}-03$ \\
\hline P080318A & 850 & 5 & $10.00 \%$ & 0.48 & 90 & 0.9975 & 60.5046 & 61.0228 & 0.5182 & 250 & 25 & 0.1 & 0 & & \\
\hline P080318A & 850 & 5 & $10.00 \%$ & 0.50 & 90 & 0.9975 & 60.5046 & 61.0228 & 0.5182 & 250 & 25 & 0.1 & 0 & & \\
\hline P080318B & 850 & 5 & $10.00 \%$ & 0.52 & 90 & 0.8134 & 61.4545 & 61.9276 & 0.4731 & 250 & 25 & 0.1 & 0 & & \\
\hline P080318C & 850 & 5 & $20.00 \%$ & 0.98 & 90 & 1.0013 & 61.4598 & 62.1254 & 0.6656 & 250 & 25 & 0.1 & 0.542 & $2.17 \mathrm{E}-03$ & 5.41E-04 \\
\hline & 850 & 5 & & & & & & & & & & & & & \\
\hline P080318D & 850 & 5 & $20.00 \%$ & 1.00 & 90 & 0.9961 & 76.1221 & 76.7712 & 0.6491 & 250 & 25 & 0.1 & 0.526 & $2.10 \mathrm{E}-03$ & $5.28 \mathrm{E}-04$ \\
\hline P080320A & 850 & 5 & $40.00 \%$ & 1.98 & 90 & 0.6767 & 61.0547 & 61.4658 & 0.4111 & 250 & 25 & 0.1 & 0 & & $0.00 \mathrm{E}+00$ \\
\hline & 850 & 5 & & & & & & & & & & & & & \\
\hline P080320B & 850 & 5 & $40.00 \%$ & 2.00 & 90 & 0.7677 & 61.6313 & 61.6313 & 0.0000 & 250 & 25 & 0.1 & & & $0.00 \mathrm{E}+00$ \\
\hline SB080320 & 850 & 1 & $5.00 \%$ & & 90 & 1.0008 & 70.6022 & 71.4048 & 0.8026 & 250 & 25 & 0.1 & 3.254 & $1.30 \mathrm{E}-02$ & $3.25 \mathrm{E}-03$ \\
\hline & & & & & & & & & & & & & & & \\
\hline SB080424 & 850 & 1 & $5.00 \%$ & 0.05 & 1st 90 & 92.36 & & & & 250 & & & & & \\
\hline SB080424 & & & & & 2nd 90 & & & & 64.88 & 250 & & & & & \\
\hline & & & & & & & & & & & & & & & \\
\hline SB080424 & & & & & 90 & 1.0005 & 61.0483 & 61.7588 & 0.7105 & 250 & 25 & 0.1 & 4.426 & $1.77 \mathrm{E}-02$ & $4.42 \mathrm{E}-03$ \\
\hline SB080424(Titrate again) & & & & & 90 & 1.0005 & 61.0483 & 61.7588 & 0.7105 & 250 & 25 & 0.1 & 4.214 & $1.69 \mathrm{E}-02$ & $4.21 \mathrm{E}-03$ \\
\hline $\mathrm{P} 080424 \mathrm{~A}$ & 850 & 5 & $7.50 \%$ & 0.375 & 90 & 0.9994 & 61.6370 & 62.3531 & 0.7161 & 250 & 25 & 0.1 & 2.298 & $9.19 \mathrm{E}-03$ & $2.30 \mathrm{E}-03$ \\
\hline P080424B & 850 & 5 & $7.50 \%$ & 0.375 & 90 & 1.0011 & 61.0088 & 61.7409 & 0.7321 & 250 & 25 & 0.1 & 2.180 & $8.72 \mathrm{E}-03$ & $2.18 \mathrm{E}-03$ \\
\hline P080424C & 850 & 5 & $10.00 \%$ & 0.5 & 90 & 1.0010 & S4 & & & 250 & 25 & 0.1 & 1.692 & $6.77 \mathrm{E}-03$ & $1.69 \mathrm{E}-03$ \\
\hline P080424D & 850 & 5 & $10.00 \%$ & 0.5 & 90 & 1.0003 & S5 & & & 250 & 25 & 0.1 & 1.660 & $6.64 \mathrm{E}-03$ & $1.66 \mathrm{E}-03$ \\
\hline & & & & & & & & & & & & & & & \\
\hline SB080515 & 850 & 1 & $5.00 \%$ & & 90 & 1.0085 & 61.6334 & 62.3257 & 0.6923 & 250 & 25 & 0.1 & 5.028 & $2.01 \mathrm{E}-02$ & $4.99 \mathrm{E}-03$ \\
\hline SB080515(titrate again) & & & & & 90 & 1.0085 & 61.6334 & 62.3257 & 0.6923 & 250 & 25 & 0.1 & 4.918 & $1.97 \mathrm{E}-02$ & $4.88 \mathrm{E}-03$ \\
\hline P080530A & 850 & 5 & $15.00 \%$ & 0.75 & 90 & 1.0008 & 61.0429 & 61.7404 & 0.6975 & 250 & 25 & 0.1 & 1.184 & $4.74 \mathrm{E}-03$ & $1.18 \mathrm{E}-03$ \\
\hline P080530B & 850 & 5 & $15.00 \%$ & 0.75 & 90 & 0.9994 & 60.9970 & 61.6935 & 0.6965 & 250 & 25 & 0.1 & 1.014 & $4.06 \mathrm{E}-03$ & $1.01 \mathrm{E}-03$ \\
\hline & & & & & & & & & & & & & & & \\
\hline P080530C & 850 & 5 & $20.00 \%$ & 1 & 90 & 0.9706 & 61.4357 & 62.0991 & 0.6634 & 250 & 25 & 0.1 & 0.854 & $3.42 \mathrm{E}-03$ & $8.80 \mathrm{E}-04$ \\
\hline P080530D & 850 & 5 & $20.00 \%$ & 1 & 90 & 0.9711 & 61.6373 & 62.2853 & 0.6480 & 250 & 25 & 0.1 & 0.534 & $2.14 \mathrm{E}-03$ & $5.50 \mathrm{E}-04$ \\
\hline P080626A & 850 & 5 & $1000 \%$ & & 90 & 10025 & $61.6385(\mathrm{~S} 1)$ & & & 250 & 25 & 01 & 1100 & 4 40E-03 & $110 \mathrm{E}-03$ \\
\hline P080626B & 850 & 5 & $10.00 \%$ & & 90 & 1.0022 & $70.6074(\mathrm{~N} 1)$ & & & 250 & 25 & 0.1 & 1.372 & $5.49 \mathrm{E}-03$ & $1.37 \mathrm{E}-03$ \\
\hline SB080721 & 850 & 1 & $5.00 \%$ & & 90 & 1.0011 & $70.9806(\mathrm{~N} 2)$ & & & 250 & 25 & 0.1 & 3.806 & $1.52 \mathrm{E}-02$ & $3.80 \mathrm{E}-03$ \\
\hline
\end{tabular}




\section{APPENDIX C \\ ChemCad Process Simulation Details}

Chemstations ChemCad ${ }^{\mathrm{TM}}$ is a commercially available chemical process simulation program. Details can be found at www.chemstations.com It has an extensive thermodynamic database and numerous thermodynamic models for determining phase equilibrium. It can also model electrolytes in aqueous solution, which is required for this project. Such simulators are especially useful when there are recycle steams present, which require iterative calculations.

For the process flow sheet shown in Figure 6, the input data and unit specifications are detailed here. Although Chemcad contains an extensive database, black liquor is not among the species. The black liquor was modeled as the sum of the inorganic compounds (which are found in the database), plus a model molecule which represents the organic fraction of the liquor, plus water. For the liquor used in this study the molar ratios of $\mathrm{C} / \mathrm{H} / \mathrm{O}$ led to a compound with formula $\mathrm{C}_{16} \mathrm{H}_{19} \mathrm{O}_{4}$. The properties of this model molecule ("Organic Black Liquor") were copied from a species with the same formula. The resulting black liquor feed stream (1) composition in Figure 6 is thus shown in Table $\mathrm{C}-1$. The oxygen stream was assumed to come from a low grade on-site air separation unit. Such units produce an oxygen stream with roughly $10 \%$ nitrogen. Total flow rates for all streams are shown in Table 5 in the main body of the report. 
Table C1. Model Black Liquor Properties

\begin{tabular}{|c|c|c|c|c|c|}
\hline Stream & & Black Liquo & properties: & & \\
\hline Property & Units & Overall & Vapor & Liquid & Solid \\
\hline Temperature deg & $\mathrm{C}$ & 90 & & & \\
\hline Pressure & bar & 20 & & & \\
\hline Vapor fraction & & $0.00 E+00$ & & & \\
\hline Critical T deg & $\mathrm{C}$ & 436.44 & & & \\
\hline Critical P & bar & 318.22 & & & \\
\hline Std sp. gr. ${ }^{*}$ air 1 & & 2.388 & & & \\
\hline Deg API & & -32.59 & & & \\
\hline Enthalpy & $\mathrm{kJ} / \mathrm{h}$ & $-9.24 E+08$ & $0.00 \mathrm{E}+00$ & $-3.94 E+08$ & $-5.30 E+08$ \\
\hline Molar flow & $\mathrm{kmol} / \mathrm{h}$ & 1777.141 & 0 & 1332.013 & 445.128 \\
\hline Mass flow & $\mathrm{kg} / \mathrm{h}$ & 122915 & 0 & 71199.856 & 51715.147 \\
\hline Avg. mol. wt. & & 69.164 & 0 & 53.453 & 116.18 \\
\hline Actual dens & $\mathrm{kg} / \mathrm{m} 3$ & 2347.64 & 0 & 2204.888 & 2577.378 \\
\hline Actual vol & $\mathrm{m} 3 / \mathrm{h}$ & 52.357 & 0 & 32.292 & 20.065 \\
\hline Std liq vol & $\mathrm{m} 3 / \mathrm{h}$ & 85.917 & 0 & 65.853 & 20.064 \\
\hline Std vapor & $\mathrm{m} 3 / \mathrm{h}$ & 39832.211 & 0 & 29855.265 & 9976.945 \\
\hline $\mathrm{Cp}$ & $\mathrm{kJ} / \mathrm{kg}-\mathrm{K}$ & & 0 & 1.664 & 1.067 \\
\hline Z factor & & & 0 & 2.51E-02 & \\
\hline Viscosity & $\mathrm{cP}$ & & 0 & 0.4711 & \\
\hline Thermal cond. & $\mathrm{W} / \mathrm{m}-\mathrm{K}$ & & 0 & 0.4913 & \\
\hline Surface tension & dyne/cm & & & 52.9944 & \\
\hline \multicolumn{6}{|l|}{ Flowrates in $\mathrm{kg} / \mathrm{h}$} \\
\hline Hydrogen & $\mathrm{kg} / \mathrm{h}$ & $0.00 \mathrm{E}+00$ & $0.00 \mathrm{E}+00$ & $0.00 E+00$ & $0.00 E+00$ \\
\hline Carbon Monoxide & $\mathrm{kg} / \mathrm{h}$ & $0.00 E+00$ & $0.00 E+00$ & $0.00 E+00$ & $0.00 E+00$ \\
\hline Carbon Dioxide & $\mathrm{kg} / \mathrm{h}$ & $0.00 \mathrm{E}+00$ & $0.00 \mathrm{E}+00$ & $0.00 \mathrm{E}+00$ & $0.00 \mathrm{E}+00$ \\
\hline Nitrogen & $\mathrm{kg} / \mathrm{h}$ & $0.00 E+00$ & $0.00 E+00$ & $0.00 \mathrm{E}+00$ & $0.00 \mathrm{E}+00$ \\
\hline Oxygen & $\mathrm{kg} / \mathrm{h}$ & $0.00 E+00$ & $0.00 E+00$ & $0.00 E+00$ & $0.00 E+00$ \\
\hline Hydrogen Sulfide & $\mathrm{kg} / \mathrm{h}$ & $0.00 E+00$ & $0.00 \mathrm{E}+00$ & $0.00 \mathrm{E}+00$ & $0.00 E+00$ \\
\hline Water & $\mathrm{kg} / \mathrm{h}$ & $2.05 E+04$ & $0.00 \mathrm{E}+00$ & $2.05 E+04$ & $0.00 E+00$ \\
\hline Carbon & $\mathrm{kg} / \mathrm{h}$ & $0.00 E+00$ & $0.00 E+00$ & $0.00 E+00$ & $0.00 E+00$ \\
\hline Sodium Carbonate & $\mathrm{kg} / \mathrm{h}$ & $3.25 E+04$ & $0.00 E+00$ & $0.00 E+00$ & $3.25 E+04$ \\
\hline Sodium Sulfate & $\mathrm{kg} / \mathrm{h}$ & $1.89 \mathrm{E}+04$ & $0.00 \mathrm{E}+00$ & $0.00 \mathrm{E}+00$ & $1.89 E+04$ \\
\hline Sodium Sulfide & $\mathrm{kg} / \mathrm{h}$ & $0.00 E+00$ & $0.00 E+00$ & $0.00 E+00$ & $0.00 E+00$ \\
\hline Sodium Chloride & $\mathrm{kg} / \mathrm{h}$ & $3.23 E+02$ & $0.00 E+00$ & $0.00 E+00$ & $3.23 E+02$ \\
\hline$(\mathrm{Na2O})(\mathrm{TiO} 2) 3$ & $\mathrm{~kg} / \mathrm{h}$ & $0.00 E+00$ & $0.00 E+00$ & $0.00 E+00$ & $0.00 E+00$ \\
\hline$(\mathrm{Na} 2 \mathrm{O})(\mathrm{TiO} 2) 6$ & $\mathrm{~kg} / \mathrm{h}$ & $0.00 E+00$ & $0.00 \mathrm{E}+00$ & $0.00 E+00$ & $0.00 E+00$ \\
\hline (Na2O)4(TiO2)5 & $\mathrm{kg} / \mathrm{h}$ & $0.00 E+00$ & $0.00 E+00$ & $0.00 E+00$ & $0.00 E+00$ \\
\hline Ammonia & $\mathrm{kg} / \mathrm{h}$ & $1.62 E+02$ & $0.00 E+00$ & $1.62 E+02$ & $0.00 E+00$ \\
\hline Org Black Liquor & $\mathrm{kg} / \mathrm{h}$ & $5.04 \mathrm{E}+04$ & $0.00 \mathrm{E}+00$ & $5.04 \mathrm{E}+04$ & $0.00 E+00$ \\
\hline Sodium Hydroxide & $\mathrm{kg} / \mathrm{h}$ & $0.00 \mathrm{E}+00$ & $0.00 \mathrm{E}+00$ & $0.00 E+00$ & $0.00 E+00$ \\
\hline Methane & $\mathrm{kg} / \mathrm{h}$ & $0.00 E+00$ & $0.00 E+00$ & $0.00 E+00$ & $0.00 E+00$ \\
\hline Silicon Dioxide & $\mathrm{kg} / \mathrm{h}$ & $1.35 \mathrm{E}+02$ & $0.00 \mathrm{E}+00$ & $1.35 \mathrm{E}+02$ & $0.00 \mathrm{E}+00$ \\
\hline
\end{tabular}


The gasifier includes the following six reactions:

1) $\mathrm{C}_{16} \mathrm{H}_{11} \mathrm{O}_{4}+6 \mathrm{O}_{2} \rightarrow 16 \mathrm{CO}+9.5 \mathrm{H}_{2} \quad$ Conv $=1, \Delta \mathrm{H}=-1110 \mathrm{~kJ} / \mathrm{mol} \mathrm{C}_{16} \mathrm{H}_{11} \mathrm{O}_{4}$

2) (NT6) $+\mathrm{Na}_{2} \mathrm{CO}_{3} \rightarrow 2(\mathrm{NT} 3)+\mathrm{CO}_{2} \quad \mathrm{Conv}=1, \Delta \mathrm{H}=15 \mathrm{~kJ} / \mathrm{mol} \mathrm{NT} 6$

3) $5(\mathrm{NT} 3)+9 \mathrm{Na}_{2} \mathrm{CO}_{3} \rightarrow 3(\mathrm{~N} 4 \mathrm{~T} 5)+7 \mathrm{CO}_{2} \quad \mathrm{Conv}=0.85, \Delta \mathrm{H}=62 \mathrm{~kJ} / \mathrm{mol} \mathrm{Na}_{2} \mathrm{CO}_{3}$

4) $2 \mathrm{CH}_{4}+\mathrm{O}_{2} \rightarrow 4 \mathrm{H}_{2}+2 \mathrm{CO} \quad \mathrm{Conv}=1, \Delta \mathrm{H}=-71.4 \mathrm{~kJ} / \mathrm{mol}$

5) $\mathrm{H}_{2}+\mathrm{CO}+\mathrm{O}_{2} \rightarrow \mathrm{CO}_{2}+\mathrm{H}_{2} \mathrm{O}$ Conv $=1, \Delta \mathrm{H}=-524.8 \mathrm{~kJ} / \mathrm{mol}$

6) $\mathrm{H}_{2}+\mathrm{CO}_{2} \leftarrow \rightarrow \mathrm{CO}+\mathrm{H}_{2} \mathrm{O}$ Water-gas-shift equilibrium

The methane reaction was included in case we needed to add some methane to the gasifier to increase the temperature. There should be reactions to reduce the sodium sulfate in the liquor to sodium sulfide, and then form some hydrogen sulfide, however these reactions were inadvertently overlooked. It is of little consequence as the sulfur reactions were not the focus of the work. But it would have been interesting to track the fate of sulfur.

The gas-solid separator leaving the gasifier, and the solid-liquid separator are simple phase separators. For the letter we assume $5 \%$ of the water leaves with the solids, which is low without the use of a centrifuge. For the hydrogen membrane, it is assumed that $95 \%$ of the hydrogen is recycled back the gasifier.

The leacher is where the N4T5 is hydrolyzed and reforms NT3, NT6, and white liquor. The reaction is:

7) $9(\mathrm{~N} 4 \mathrm{~T} 5)+26 \mathrm{H}_{2} \mathrm{O} \rightarrow 5 \mathrm{NT} 3+5 \mathrm{NT} 6+52 \mathrm{NaOH}$

For the divider leading to the NPE acid wash, $15 \%$ of the solids are diverted for NPE removal. In the acid wash, the NPE's are assumed to be $100 \%$ dissolved and removed by acid.

The above information as well as the results in Table 5, should be sufficient for someone skilled with ChemCad to reproduce the simulation. 


\section{APPENDIX D \\ Economic Assessment}

We intend to compare the proposed process developed in this work (which we will refer to as CFBBLG for Circulating Fluid Bed Black Liquor Gasification) to Larson's [21] cost-benefit study on the use of pressurized HTBLG in conjunction with a conventional lime cycle for caustic recovery.

The reference mill used for this study is an integrated pulp and paper mill producing uncoated freesheet paper from a 65/35 mix of hardwood and softwood. The mill produces about 5.4 MM lbs/day of black liquor solids (BLS). The HTBLG case data from the Larson Study is used for the base case in this study. Table D1 shows the basic data used for the study, and Table D2 shows the chemical recovery data. We will estimate the NPV and IRR for the proposed titanate process assuming the process in the Larson study is already being built. The tables that follow provide the method used in estimating the cost of a titanate recycle system [9] consisting of three leaching stages, and acid wash system, and associated pumps and piping. We will then adjust these results to provide a rough estimate of the total installed cost for the current system consisting of a single leaching stage, acid wash, associate dipping, and a membrane gas separator.

Table D1

\section{Reference Mill Basis Data}

Product Flow

Unbleached Pulp Rate

Mill Hardwood/Softwood Mix

Digester Yield

Wood To Process (91\% of total)

Hog Fuel (9\% of total)

Total Wood Used

Black Liquor Solids Concentration

BL Solids Flow Rate

BL Specific Gravity

BL Flow

BL Energy Content

MW, HHV 394.7

BL Solids Composition, mass $\%$

\begin{tabular}{|c|c|}
\hline md mtpd & 1725 \\
\hline bd stpd & 1580 \\
\hline$\% \mathrm{HW}, \% \mathrm{SW}$ & $65 \% \mathrm{HW}, 35 \% \mathrm{SW}$ \\
\hline$\%$ for softwood & 48.75 \\
\hline$\%$ for hardwood & 49.75 \\
\hline bd stpd & 3,208 \\
\hline bd stpd & 317 \\
\hline bd stpd & 3,525 \\
\hline$\%$ solids & 80 \\
\hline lb BLS per day & $5,419,646$ \\
\hline kg BLS per day & $2,458,311$ \\
\hline \multirow[t]{2}{*}{ BLS mtpd } & 2,458 \\
\hline & 1.428 \\
\hline lpm & 1,495 \\
\hline \multicolumn{2}{|c|}{$\mathrm{kJ}$ per $\mathrm{kg}$ of BLS (HHV) 13,874} \\
\hline \multicolumn{2}{|c|}{ Btu per lb of BLS (HHV) 5,966 } \\
\hline $\mathrm{C}$ & 32.97 \\
\hline $\mathrm{H}$ & 3.70 \\
\hline $\mathrm{O}$ & 36.88 \\
\hline $\mathrm{S}$ & 4.27 \\
\hline $\mathrm{Na}$ & 20.03 \\
\hline $\mathrm{K}$ & 1.93 \\
\hline $\mathrm{Ash} / \mathrm{Cl}$ & 0.22 \\
\hline
\end{tabular}


Table D2

HTBLG Chemical Recovery Data

$\begin{array}{lll}\text { Wood charge, mt/d } & 3,198 & \\ \text { Causticization efficiency, \% } & 81 \% & \\ \text { Active Alkali (as Na2O), mtpd } & 584 & \\ \text { Active Alkali (as Na2O)/Wood } & 0.183 & \\ \text { Lime availability, \% } & 90 \% & \\ \text { White Liquor in lime mud, mtpd } & 749 & \\ \text { Water for slaking, mtpd 137.5 } & & \\ \text { Green Liquor TTA, g/l as Na2O } & 130 & \\ \text { Water in White Liquor, mtpd } & 5,240 & \\ \text { White Liquor TTA, g/l as Na2O } & 133 & \text { mtph } \\ \text { TTA in Weak Wash, mtpd } & 87.9 & 102 \\ & & 4.38 \\ \text { Black Liquor } & \text { mtpd } \\ \text { BLS } & 2,458 & 20.52 \\ \text { S } & 105 & 1.98 \\ \text { Na } & 492.4 & 0.11 \\ \text { K } & 47.5 & 0.11 \\ \text { Cl } & 2.7 & \\ \text { Ash } & 2.7 & \text { mtph } \\ * \text { Smelt } & & 5.0 \\ \text { Na2S } & \text { mtpd } \\ \text { NaOH } & 120.0 \\ \text { Na2CO3 } & 20.0 \\ \text { NaCl } & 1005.6 & 0.8 \\ \text { Ash } & 4.5 & 41.9 \\ \text { TTA } & 2.7 & 0.2 \\ & 1152.8 & 0.1 \\ \text { NTh } & & 48.0\end{array}$

*Note - the Larson Study assumes that potassium and sodium are equivalent and both elements are included in the smelt sodium compounds.

$\begin{array}{ll}\text { Abbreviations } & \\ \text { Black Liquor Solids } & \text { BLS } \\ \text { Bone dry } & \text { bd } \\ \text { Hard Wood } & \text { HW } \\ \text { Soft Wood } & \text { SW } \\ \text { High Temp BLG } & \text { HTBLG } \\ \text { Machine Dry } & \text { md } \\ \text { Metric Tons } & \mathrm{mt} \\ \text { Metric Tons per Day } & \mathrm{mtpd} \\ \text { Total Titratable Alkali } & \text { TTA } \\ \text { Higher Heating Value } & \text { HHV } \\ \text { Short Tons per Day } & \text { stpd } \\ \text { Liters per Minute } & \text { lpm }\end{array}$

The CFBBLG case developed here leads to full direct causticizing (i.e. no lime), hence the conventional caustic plant is shut down. As discussed previously for the economical use of titanate, it must be recovered and recycled back to the black liquor prior to gasification as shown in Figure 6. Following smelt dissolving, titanate remains in the green liquor as a suspended solid. By assuming physical properties of the titanate being similar to lime mud, we can extrapolate to a mill-scale process utilizing a large leaching 
tank for 60 minutes reaction residence time, followed by disc filtration. The aqueous phase is white liquor for pulping, and the solids are remixed with black liquor and fed to the gasifier. A portion of the titanate solids stream (10\%) is transferred to an acid slurry mix tank. The purpose of the acid slurry tank is to mix hydrochloric acid with the titanate solids. The acid dissolves the NPEs from the titanate. The acid slurry is transferred to a disc filter. Filtrate from the NPE purge filter flows by gravity to an NPE purge filtrate tank. Caustic is added to neutralize the acid. The neutralized filtrate then flows to the sewer. Solids from the NPE purge filter are conveyed to a new black liquor mix tank. Titanium dioxide makeup is added to the black liquor mix tank as well via a screw conveyor. It is assumed that the mill already has available hydrochloric acid and caustic make-down and delivery systems. Potassium remains in the system either as potassium titanate or potassium hydroxide and carbonate. Potassium lowers the melting point of recovery boiler ash and is a primary cause of boiler tube pluggage in Tomlison recovery boilers. In a CFBBLG system, the potassium poses no problem. A new agitated heavy $(50 \%)$ black liquor mix tank is required to recycle the titanate prior to the black liquor concentrator. This allows the $85 \%$ solids titanate recycle stream to be uniformly mixed prior to concentrating the black liquor to $80 \%$ solids for gasification. The titanate suspended solids flow is substantial, adding about $40 \%$ to the overall mass flow of the [dry basis] black liquor. The black liquor volume flow increases about $20 \%$. Although no increase to the evaporation capacity of the black liquor concentrator is required, modifications are required to increase the hydraulic capacity. Primarily pump and motor upgrades are required. An allowance will be included in the capital estimate to cover concentrator upgrades for the increased liquor flow. The additional suspended solids should enhance the crystallization process and reduce fouling for $80 \%$ solids liquor production by providing sites for crystallization to take place rather than on heat transfer surface areas.

\section{Total Installed Cost}

The Sinquefield/Cantrell study [9] utilized Jacob's extensive database of equipment pricing. The estimates were (and will be) $+/-30 \%$ accuracy factored total installed cost (TIC). The estimates will be based on preliminary process flow diagrams, priced equipment lists, and project scope descriptions. The key flow rates are shown in Table D3 below.

Table D3

\begin{tabular}{ll}
\multicolumn{1}{c}{ Titanate ChemCad Balance Basis and Assumptions } \\
Smelt & (w/o potassium) \\
$\mathrm{Na} 2 \mathrm{CO} 3, \mathrm{mt} / \mathrm{hr}$ & 4.76 \\
$\mathrm{NaOH}, \mathrm{mt} / \mathrm{hr}$ & 0.79 \\
$\mathrm{Na} 2 \mathrm{~S}, \mathrm{mt} / \mathrm{hr}$ & 4.73 \\
$\mathrm{HCl}, \mathrm{mt} / \mathrm{hr}$ & 0.67 \\
$\mathrm{NPEs}(\mathrm{Dissolved}), \mathrm{mt} / \mathrm{hr}$ & 3.15 \\
Inerts (Suspended), $\mathrm{mt} / \mathrm{hr}$ & 1.46 \\
Black Liquor Sodium Carbonate Converted, \% & 88.0 \\
Leaching Caustic Recovery, \% & 86.1 \\
Titanate Split to NPE Purge, \% & 10 \\
HCl ratio to Treated Solids, $\mathrm{kg} / \mathrm{kg}$ & 0.1
\end{tabular}


Equipment pricing in [9] was obtained from Andritz for disc filters and leaching tank agitators. Pump pricing was obtained from ITT Goulds. All other equipment pricing was obtained from Jacobs' historical database. Piping, structural, electrical, and controls material and equipment were factored based on the process equipment direct cost. The estimates assumed an engineering, procurement, and construction management (EPC) type contract to execute the project. The estimates assumed a site in the southeastern United States, non-union, and no escalation was included. Other estimating assumptions are listed in Table D4 below.

\section{Table D4 \\ Capital Estimates Assumptions}

$\begin{array}{ll}\begin{array}{l}\text { General Information } \\ \text { Basis of Premium Time }\end{array} & \begin{array}{l}\text { 10\% of the hours worked on 50-hour weeks } \\ \text { Per Diem Requirements }\end{array} \\ \begin{array}{l}\text { Per Diem at } \$ 5.00 \text { per hour on } 100 \% \text { of hours } \\ \text { Constructability }\end{array} & \begin{array}{l}\text { Unknown - depending on site } \\ \text { 20\% of direct labor }\end{array} \\ \text { Non Payroll Insurance, Taxes, Permits } \\ \text { Sales Tax } & 5 \% \text { of TIC } \\ \text { Building Permits } & \text { Allowance provided for building permits } \\ \text { Environmental Permits } & \text { Unknown - depending on site } \\ \text { Construction Management } & 4 \% \text { of TIC } \\ \text { Engineering } & 10 \% \text { of TIC for titanate } \\ \text { Outside Consultants } & \text { DCS configuration, soils testing, and outside } \\ & \text { survey } \\ \text { Owner's Cost } & 4 \% \text { of TIC } \\ \text { Spare Parts } & 5 \% \text { of equipment cost } \\ \text { Check-Out \& Commissioning } & 5 \% \text { of engineering and allowances for vendors } \\ \text { Allowance for Unforeseen } & 10 \% \text { on all costs which equates to } 8.33 \% \text { of TIC } \\ \text { Escalation } & 0 \% \text {, Estimated in today's costs (2009) }\end{array}$

The net result of the above cost model yielded the prices shown in Table D5 below. Details can be found in [9]. 
Table D5

Summary of Total Installed Cost of [9]

\begin{tabular}{|c|c|c|}
\hline CONSTRUCTION DIRECT COSTS & & Totals \\
\hline MAJOR EQUIPMENT & & $\$ 13,285,767$ \\
\hline DEMOLITION & & $\$ 0$ \\
\hline SITE EARTHMOVING & & $\$ 0$ \\
\hline SITE IMPROVEMENTS & & $\$ 0$ \\
\hline PILING, CAISSONS & & $\$ 0$ \\
\hline BUILDINGS & & $\$ 630,000$ \\
\hline CONCRETE & & $\$ 398,573$ \\
\hline MASONRY, REFRACTORY & & $\$ 0$ \\
\hline STRUCTURAL STEEL & & $\$ 262,660$ \\
\hline ROOFING AND SIDING & & $\$ 0$ \\
\hline FIRE PROOFING & & $\$ 0$ \\
\hline PROCESS DUCTWORK (NON-BUILDING) & & $\$ 0$ \\
\hline PIPING & & $\$ 2,759,363$ \\
\hline INSULATION - PIPE, EQUIPMENT \& DUCTWORK & & $\$ 0$ \\
\hline INSTRUMENTATION & & $\$ 2,125,723$ \\
\hline ELECTRICAL & & $\$ 611,357$ \\
\hline PAINTING, PROTECTIVE COATINGS & & $\$ 0$ \\
\hline FURNITURE, LAB \& SHOP EQUIPMENT & & $\$ 0$ \\
\hline Total Direct Costs & & $\$ 20,073,442$ \\
\hline \multicolumn{3}{|l|}{ CONSTRUCTION INDIRECT } \\
\hline CONSTRUCTION SUPPORT LABOR & & $\$ 292,456$ \\
\hline $\begin{array}{l}\text { TEMPORARY CONSTRUCTION FACILITIES (IN WAGE } \\
\text { RATES) }\end{array}$ & & $\$ 0$ \\
\hline PREMIUM TIME & & $\$ 192,365$ \\
\hline CRAFT FRINGE BENEFITS (IN WAGE RATES) & & $\$ 0$ \\
\hline CRAFT PER DIEM (\$5 PER HOUR ON $100 \%$ OF THE HOURS) & & $\$ 382,367$ \\
\hline PAYROLL TAXES \& INSURANCE (IN WAGE RATES) & & $\$ 0$ \\
\hline SMALL TOOLS (IN WAGE RATES) & & $\$ 0$ \\
\hline CONSUMABLE SUPPLIES (IN WAGE RATES) & & $\$ 0$ \\
\hline CONSTRUCTION EQUIPMENT (IN WAGE RATES) & & $\$ 0$ \\
\hline FIELD STAFF (IN WAGE RATES) & & $\$ 0$ \\
\hline NON-PAYROLL TAX, INSURANCE \& PERMITS & & $\$ 156,897$ \\
\hline CONSTRUCTION HOME OFFICE COST (IN WAGE RATES) & & $\$ 0$ \\
\hline CRAFT START-UP ASSISTANCE & & $\$ 20,304$ \\
\hline CONTRACTOR'S CONSTRUCTION OVERHEAD \& FEE & & $\$ 835,157$ \\
\hline $\begin{array}{lc} & \text { Total Indirect }\end{array}$ & & $\$ 1,879,546$ \\
\hline Total Construction Costs (TCC) & & $\$ 21,952,988$ \\
\hline \multicolumn{3}{|l|}{ PROJECT INDIRECT } \\
\hline CONSTRUCTION MANAGEMENT & $4.00 \%$ of $\mathrm{TIC}$ & $\$ 1,262,297$ \\
\hline ENGINEERING PROFESSIONAL SERVICES & $10.00 \%$ of TIC & $\$ 3,156,840$ \\
\hline STUDY COST & $0.00 \%$ of $\mathrm{TIC}$ & $\$ 0$ \\
\hline OUTSIDE CONSULTANT SERVICES & $0.22 \%$ of TIC & $\$ 70,000$ \\
\hline OWNER'S COST & $4.00 \%$ of TIC & $\$ 1,262,297$ \\
\hline SPARE PARTS & $2.16 \%$ of TIC & $\$ 680,189$ \\
\hline NON-CRAFT START-UP ASSISTANCE & $0.98 \%$ of $\mathrm{TIC}$ & $\$ 307,842$ \\
\hline ALLOWANCE FOR UNFORESEEN & $9.09 \%$ of TIC & $\$ 2,869,245$ \\
\hline 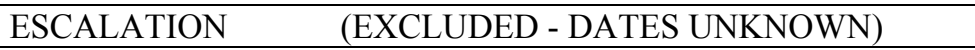 & $0.00 \%$ of TIC & $\$ 0$ \\
\hline ROUND OFF & & $(\$ 697)$ \\
\hline Total Installed Cost (TIC) & & $\$ 31,561,000$ \\
\hline
\end{tabular}


To use the extensive work done in [9] for an estimate of the titanate system proposed here we will make the following corrections to the model in Table D5:

- Add \$3MM to 'major equipment' for the membrane gas separator.

- Reduce the $\$ 9.5 \mathrm{MM}$ cost of the leaching system agitators and pumps [9] by $60 \%$ to correct for one leaching stage versus three leaching stages in [9].

- Correct the TCC from 2006 to current price. The Chem Engr Plant cost index for Sept 2006 was 513, and for Sept. 2009 was 525.7

- Assume other construction direct and indirect costs are close enough to use for this study.

Adding the above corrections to Table D5 produces the results in Table D6 below. The TIC of $\$ 27,477,000$ will be used to compute the IRR and NPV of the current proposed design.

Table D6

Summary of Total Installed Cost of Proposed Process

\begin{tabular}{|l|r|r|}
\hline Total Construction Costs, TCC & & $\$ 19,111,877$ \\
\hline Construction Management & $4.00 \%$ of TIC & $\$ 764,388$ \\
\hline Engineering Professional Services & $10.00 \%$ of TIC & $\$ 1,911,636$ \\
\hline Study Cost & $0.00 \%$ of TIC & $\$ 0$ \\
\hline Outside Consultant Services & $0.22 \%$ of TIC & $\$ 42,389$ \\
\hline Owner's Cost & $4.00 \%$ of TIC & $\$ 764,388$ \\
\hline Spare Parts & $2.16 \%$ of TIC & $\$ 411,891$ \\
\hline Non-Craft Start-Up Assistance & $0.98 \%$ of TIC & $\$ 186,415$ \\
\hline Allowance for Unforeseen & $9.09 \%$ of TIC & $\$ 1,737,482$ \\
\hline Escalation (excluded - dates unknown) & $0.00 \%$ of TIC & $\$ 0$ \\
\hline Round Off & & $\mathbf{\$ 3 3 1 2}$ \\
\hline Total Installed Cost (TIC) & & $\mathbf{\$ 2 7 , 4 7 7 , 0 0 0}$ \\
\hline
\end{tabular}

\section{Operating Costs}

Next we estimate the operating costs for the 25 year project life, and from that, calculate the IRR and NPV. Table D7 shows the chemicals, fuel oil, and electricity costs based on 2009 prices.

Table D7

Chemicals, Fuel Oil, and Electricity Costs (2009)

\#6 Fuel Oil , \$/MMBtu

Electricity, \$/MWh

Titanium Dioxide, \$/mt

Hydrochloric Acid, \$/mt

Sodium Hydroxide, $\$ / \mathrm{mt}$
$\$ 14.00$

$\$ 70.00$

$\$ 480.00$

$\$ 135.00$

$\$ 370.00$ 
Table D8 shows chemicals, fuel oil, and electricity usage or savings as compared to the base case (i.e. the costs over and above the base case of a BLG-based recovery island using a lime cycle).

Table D8

Annual Chemicals, Fuel Oil, and Electricity Usages [9]

$\begin{array}{ll}\text { Fuel Oil Savings 217,386 } & 1,086,928 \mathrm{MMBtu} / \mathrm{yr} \\ \text { Electricity Savings 4,310 } & 7,038 \mathrm{MWh} / \mathrm{yr} \\ \text { Titanium Dioxide Usage } & 3,951 \mathrm{mt} / \mathrm{yr} \\ \text { Hydrochloric Acid Usage } & 5,559 \mathrm{mt} / \mathrm{yr} \\ \text { Sodium Hydroxide Usage } & 3,912 \mathrm{mt} / \mathrm{yr}\end{array}$

Table D9 shows the costs or savings items. Avoided cost savings are treated as positive cash flow. The annual maintenance cost for the base case is based on $5 \%$ of the capital cost of a new lime kiln and caustic plant of similar capacity. This capital cost is approximately $\$ 35,000,000$.

Table D9

Annualized O\&M Costs

\begin{tabular}{lll} 
& \multicolumn{2}{c}{ Annual \$ } \\
Avoided Cost Savings & Base & Titanate \\
$\begin{array}{l}\text { Avoided Lime Kiln Fuel Oil (@\$10/MMBtu) } \\
\text { Avoided Electricity Purchases }\end{array}$ & \\
Total & & $10,869,280$ \\
& & 422,282 \\
Direct Operating Costs & $11,291,562$ \\
Titanate & \\
Hydrochloric Acid & $1,896,391$ \\
Sodium Hydroxide & 750,454 \\
Incremental Waste Treatment Costs (.10 KW/lpm) & $1,447,375$ \\
Operations \& Maintenance & 30,521 \\
Total & $1,750,000$ & $1,373,850$ \\
& $1,750,000$ & $5,498,591$
\end{tabular}

Both the internal rate of return (IRR) and net present value (NPV) analyses will be performed relative to the base case. The key inputs to the analyses are the TIC for the titanate system, and the net difference in operating costs between the titanate system and the lime cycle. Table D10 shows the economic assumptions used for the analyses. 
Table D10

Economic Assumptions

Financial Parameters

Annual Inflation Rate

$4.0 \%$

Debt Fraction of Capital

$50 \%$

Equity Fraction of Capital $\quad 50 \%$

Interest Rate on Debt $\quad 8.0 \%$

Return on Equity $\quad 15 \%$

Resulting Discount Rate used for NPV calculations $\quad 9.9 \%$ (after tax)

Income Tax Rate (combined Federal \& State) $\quad 40 \%$

Economic Life (years)

Depreciation Method

25

Construction Time

20-year MACRS ${ }^{1}$

$1 \mathrm{yr}$

Mill Assumptions

Annual Operating Hours

8,330

Annual O\&M Costs, \% of Capital Cost

$5 \%$

Start-up Assumptions

Year 1 of Operation

$100 \%$

(1 - Modified Accelerated Cost Recovery System (MACRS) per IRS Tax Code)

Table D11 on the following page shows the annualized costs at \$10/MMBtu for fuel. The numbers change for each value of fuel cost. The IRR is the discount rate at which the net present value (NPV) is zero. This is done using goal seek with the spreadsheet and comes out to $26.7 \%$ for an NPV of $\$ 27.8 \mathrm{M}$. Both the NPV and IRR are strongly dependent on the price of the fuel oil displaced. Lime kilns use considerable fuel in the form of bunker oil or natural gas. Table D12 shows the NPV and IRR for our proposed process as a function of the cost of displaced kiln fuel.

Table D12

NPV and IRR as a Function of Fuel Cost

\begin{tabular}{|c|c|c|}
\hline $\begin{array}{c}\text { \$MMBtu displaced } \\
\text { (i.e. oil or NG price) }\end{array}$ & NPV, \$MM & IRR, \% \\
\hline$\$ 6 /$ MBtu & $\$(6.6)$ & $4.5 \%$ \\
\hline$\$ 8$ & $\$ 10.6$ & $16.8 \%$ \\
\hline$\$ 10$ & $\$ 27.8$ & $26.7 \%$ \\
\hline$\$ 12$ & $\$ 45.0$ & $36.3 \%$ \\
\hline$\$ 14$ & $\$ 62.2$ & $46.3 \%$ \\
\hline
\end{tabular}


Table D11

Annual Costs for the Proposed Process

Titanate Case

Avoided Cost Savings

Avoided Lime Kiln Fuel Oil

Avoided Electricity Purchases

Subtotal - Avoided Cost Savings

\section{Direct Operating Cost}

Titanium Dioxide

Hydrochloric Acid

Incremental Waste Treatment Costs

Operations \& Maintenance

Subtotal - Operating Costs

\section{Financing}

Interest

Cumulative Principa

Subtotal - Financing

\section{Total Expenses Before Taxes}

Income Taxes

Total Expenses After Taxes

\section{Net Cash Flow from Operations}

Equity Capital Invested

\section{Total Net Cash Flow}

Discount Factor

NPV (\$ million)

Total Capital Invested

Discount Rate

Year --> $(13,738,500)$

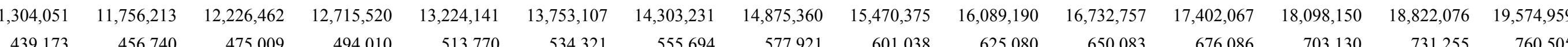

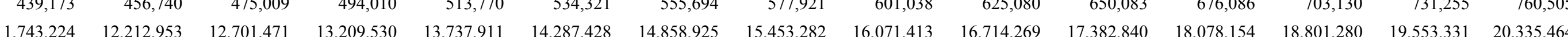

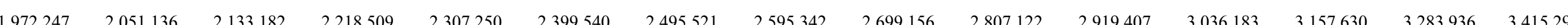

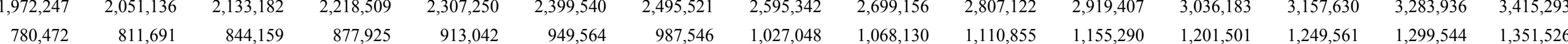

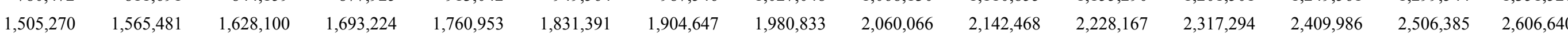

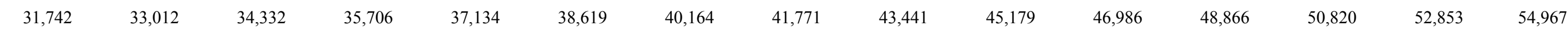
$\begin{array}{llllllllllllll}1,428,804 & 1,485,956 & 1,545,394 & 1,607,210 & 1,671,499 & 1,738,359 & 1,807,893 & 1,880,209 & 1,955,417 & 2,033,634 & 2,114,979 & 2,199,578 & 2,287,561 & 2,379,064 \\ 2,474,226\end{array}$ $\begin{array}{lllllllllllllll}5,718,535 & 5,947,276 & 6,185,168 & 6,432,574 & 6,689,877 & 6,957,472 & 7,235,771 & 7,525,202 & 7,826,210 & 8,139,259 & 8,464,829 & 8,803,422 & 9,155,559 & 9,521,781 & 9,902,652\end{array}$

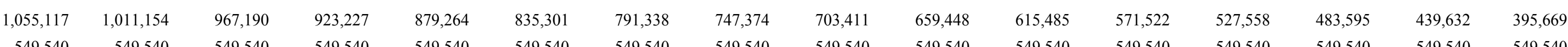

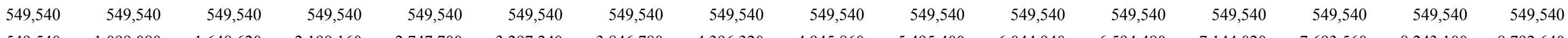

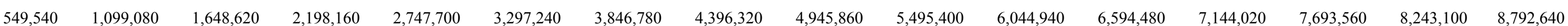

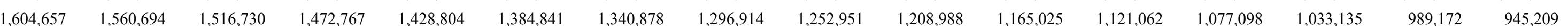

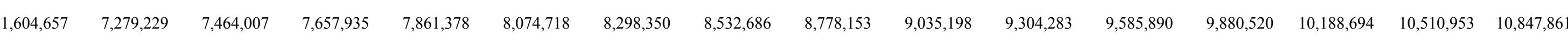

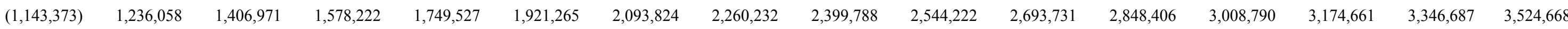

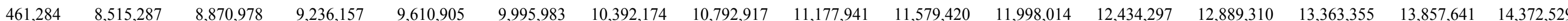

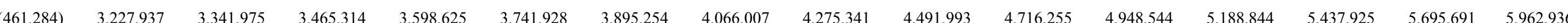

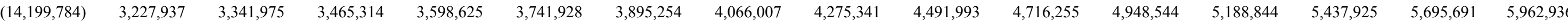
\begin{tabular}{lllllllllllllll}
1.0 & 1.1 & 1.2 & 1.3 & 1.5 & 1.6 & 1.8 & 1.9 & 2.1 & 2.3 & 2.6 & 2.8 & 3.1 & 3.4 & 3.7 \\
\hline
\end{tabular}

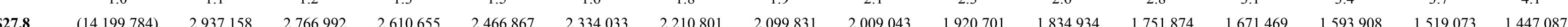


Table D11 (continued)

Titanate Case

Avoided Cost Savings

Avoided Lime Kiln Fuel Oil

Avoided Electricity Purchases

Subtotal - Avoided Cost Savings

\section{Direct Operating Costs}

Titanium Dioxide

Hydrochloric Acid

Sodium Hydroxide

Incremental Waste Treatment Costs

Operations \& Maintenance

Subtotal - Operating Costs

\section{Financing}

Interest

Principal

Cumulative Principal

Subtotal - Financing

Total Expenses Before Taxes

Income Taxes

Total Expenses After Taxes

Net Cash Flow from Operations

Equity Capital Invested

\section{Total Net Cash Flow}

Discount Factor

NPV (\$ million)

IRR

Total Capital Invested

Discount Rate

$\begin{array}{llllllllll}20,357,958 & 21,172,276 & 22,019,167 & 22,899,934 & 23,815,931 & 24,768,568 & 25,759,311 & 26,789,683 & 27,861,271 & 28,975,722\end{array}$ $\begin{array}{llllllllll}790,925 & 822,562 & 855,465 & 889,683 & 925,271 & 962,282 & 1,000,773 & 1,040,804 & 1,082,436 & 1,125,733\end{array}$

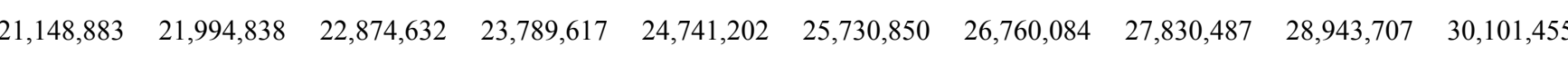

$\begin{array}{rrrrrrrrrr}3,551,905 & 3,693,981 & 3,841,740 & 3,995,410 & 4,155,226 & 4,321,435 & 4,494,293 & 4,674,064 & 4,861,027 & 5,055,468 \\ 1,405,587 & 1,461,810 & 1,520,282 & 1,581,094 & 1,644,337 & 1,710,111 & 1,778,515 & 1,849,656 & 1,923,642 & 2,000,588 \\ 2,710,906 & 2,819,342 & 2,932,116 & 3,049,401 & 3,171,377 & 3,298,232 & 3,430,161 & 3,567,367 & 3,710,062 & 3,858,465 \\ 57,166 & 59,453 & 61,831 & 64,304 & 66,876 & 69,551 & 72,333 & 75,227 & 78,236 & 81,365 \\ 2,573,195 & 2,676,123 & 2,783,168 & 2,894,495 & 3,010,275 & 3,130,686 & 3,255,913 & 3,386,149 & 3,521,595 & 3,662,459 \\ 10,298,759 & 10,710,709 & 11,139,137 & 11,584,703 & 12,048,091 & 12,530,015 & 13,031,215 & 13,552,464 & 14,094,562 & 14,658,345\end{array}$

$\begin{array}{rrrrrrrrr}351,706 & 307,742 & 263,779 & 219,816 & 175,853 & 131,890 & 87,926 & 43,963 & 0 \\ 549,540 & 549,540 & 549,540 & 549,540 & 549,540 & 549,540 & 549,540 & 549,540 & 549,540 \\ 9,342,180 & 9,891,720 & 10,441,260 & 10,990,800 & 11,540,340 & 12,089,880 & 12,639,420 & 13,188,960 & 13,738,500 \\ 901,246 & 857,282 & 813,319 & 769,356 & 725,393 & 681,430 & 637,466 & 593,503 & 549,540\end{array}$

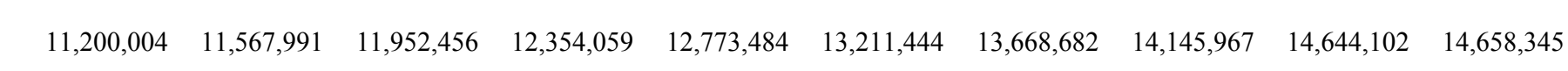

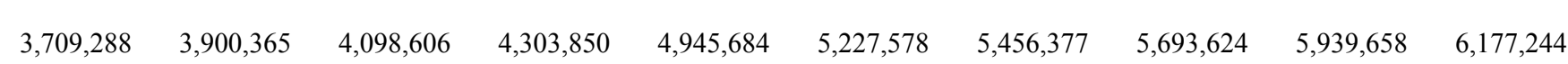
$\begin{array}{llllllllll}14,909,292 & 15,468,356 & 16,051,063 & 16,657,908 & 17,719,168 & 18,439,022 & 19,125,058 & 19,839,591 & 20,583,760 & 20,835,589\end{array}$ $\begin{array}{llllllllll}6,239,591 & 6,526,482 & 6,823,569 & 7,131,709 & 7,022,034 & 7,291,827 & 7,635,025 & 7,990,896 & 8,359,947 & 9,265,866\end{array}$ $\begin{array}{cccccccccc}6,239,591 & 6,526,482 & 6,823,569 & 7,131,709 & 7,022,034 & 7,291,827 & 7,635,025 & 7,990,896 & 8,359,947 & 9,265,866 \\ 4.5 & 5.0 & 5.5 & 6.0 & 6.6 & 7.3 & 8.0 & 8.8 & 9.6 & 10.6\end{array}$ $\begin{array}{llllllllll}1,377,822 & 1,311,349 & 1,247,536 & 1,186,417 & 1,062,941 & 1,004,349 & 956,888 & 911,273 & 867,479 & 874,870\end{array}$ 
Direct Causticizing for Black Liquor Gasification in a Circulating Fluidized Bed

Final Project Report

DE-FG36-06GO16042

\section{LAST PAGE}

